Structural performance of light steel framing panels using screw connections subjected to lateral loading

Peer-reviewed author version

GOUVEIA HENRIQUES, Jose; Rosa, Nuno; Gervasio, Helena; Santo, Paulo \& Simoes da Silva, Luis (2017) Structural performance of light steel framing panels using screw connections subjected to lateral loading. In: Thin-walled structures, 121, p. 67-88.

DOI: 10.1016/j.tws.2017.09.024

Handle: http://hdl.handle.net/1942/25836 


\title{
Structural performance of light steel framing panels using screw connections subjected to lateral loading
}

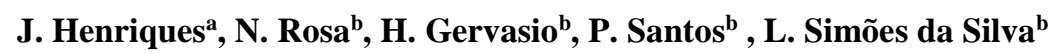 \\ ${ }^{a}$ CERG,IIW, Hasselt Universiteit, Belgium \\ ${ }^{b}$ ISISE, Civil Engineering Department, University of Coimbra, Pinhal de Marrocos, 3030 Coimbra, \\ Portugal
}

\begin{abstract}
Screw connections have an important role in the performance of Light Steel Framing (LSF) construction systems. In this paper, the behaviour LSF panels using screw connections subjected to lateral load is discussed and further insights are provided on the behaviour of such panels by experimental tests and numerical analysis.

Therefore, the main aims of this paper are: (i) to provide a discussion on the analytical, experimental and numerical assessment of steel-to-steel connections, between cold-formed elements, and steel-to- OrientedStrand-Board (OSB) connections; (ii) to discuss the results of the experimental tests carried out on braced and unbraced LSF panels subjected to lateral load; and (iii) based on a calibrated numerical model, to provide further insights into the behaviour of LSF panels.

The paper may be subdivided into two main parts. The first part of the paper addresses the behaviour of the screw connections; while the second part addresses the behaviour of braced and unbraced LSF panels, subjected to lateral loading.

The major conclusions of this paper are: (i) the results presented in this paper confirm a relevant contribution of the OSB board to the lateral stiffness of the LSF panel; (ii) the connections between OSB boards and the steel frame are the governing part of the panel resistance to lateral loading; and (iii) the significant contribution of the OSB board shows that it should not be neglected, as it is currently the case in the European standard EN 1993-1-3.
\end{abstract}

Keywords: Screw, Connection, Cold-formed, LSF panel, OSB, Lateral loading 


\section{1}

\section{Introduction}

2

Light steel framing (LSF) wall panels are increasingly being used, particularly in modular construction, not only due to its lightness and speed of assemblage but also due to its easy adaptability to most architectural and structural requirements. In the assemblage of LSF wall panels, screws are highly used given its efficiency, fast application and suitability for load bearing, fitting perfectly in the industrialized production philosophy. Due to the low thickness of cold-formed steel profiles, screw connections provide advantages such as simple design, fast installation [1] and low cost. For these reasons, they are often chosen by contractors. Only for high load bearing situations, they are not suitable due to its limited load capacity. In screw connections used in LSF, the connector is mainly subjected to shear load. Two main reasons may be identified for this type of application: i) most connections configuration consider this type of behaviour, it is the most suitable and easy connection in light steel framing; ii) the very limited resistance to tension forces of connections using screws, as the connecting layers are clamped only by the screw threads.

In this type of construction, screw connections are also used for the connection of non-structural elements or secondary members, as wood-derived boards. The latter are present in most LSF construction but often its contribution is disregarded for the design against lateral loads, such as wind and seismic actions. However, the contribution of these boards is clearly not negligible [2],[3],[4]. The lateral behaviour of sheeted cold-formed steel panels/structures is considerably dependent on the complex behaviour that occurs at each fastener location [5] and several studies are available in the literature showing the primordial role of connections in the overall performance of lightweight steel panels. Most of these studies are experimental [6],[7],[8],[9],[10],[11] but also analytical [12],[13].

Screw fasteners are easy to install, however their stiffness and strength contributions to the structural system are exceedingly difficult to quantify, this is due to complex kinematics related to, for example, screw head to plate contact and screw thread-plate interaction [14]. It is therefore very important to characterize and to control the response of this type of connections for predicting wind and seismic drift. In order to provide a deeper understanding of the behaviour of screw connections and their impact on the frame response, this paper provides a discussion on the results of experimental tests and numerical simulations performed by the authors, both on screw connections and wall panels. It is observed that the research carried out in this paper focusses on the configuration of light steel framing panels that were developed for the modular construction system CoolHaven $®[15]$. 
1 In the first part of this paper, the behaviour of screw steel-to-steel and steel-to-OSB connections is investigated. The analytical evaluation of the screw connection behaviour focussing on the design standards $[16],[17]$ is discussed and the results of an experimental programme and of the numerical simulation of single shear screw steel-to-steel connection are analysed for a detailed characterization of the connection response. In addition, the connection between OSB board and steel is analysed based on experimental tests and on the analytical formulae proposed in the EN 1995-1-1 [18]. In the second part of the paper, the behaviour of cold-formed steel panels using screw connections subjected to lateral loading is investigated and discussed by means of analytical models, experimental tests and numerical simulations.

To enable the numerical simulations, a numerical model for the steel panel is developed. This model is calibrated and validated by the results of the experimental tests.

Then the numerical model is further used to evaluate the impact of additional bracing systems, like the use standard diagonal steel strips bracings. Therefore, the contribution of the bracing system is assessed by comparing the performance of the unbraced panel frame with the OSB board braced panel frame and panel frame braced using diagonal steel stripes.

\section{Behaviour of screw connections in shear in light steel framing panels}

\subsection{Steel-to-steel screw connections}

\subsubsection{General}

In LSF the behaviour of connection is strongly influenced by the thickness of the members (thin-walled), which are characterized by a small stiffness [19]. Consequently, design equations differ from those used in connections with thicker members. The main particularity of screw connections is that the screw works without nut (Figure 1). This implies that the connection depends strongly on the mechanical interface between the thread and the connected plates. This type of connections has a significant screw rotation, especially when using a single screw, because the restrain, which could be provided by the nut, is not present. In connections using more than one row of screws, the screw rotation depends on the pitch distance $[20]$. 


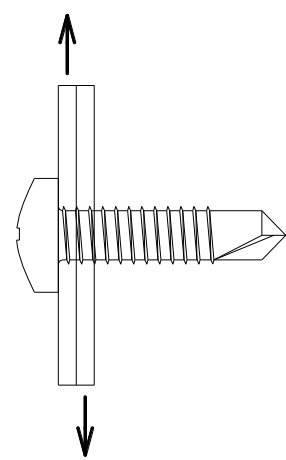

Figure 1: Shear screw connection

The load transfer mechanism in screw connections is similar to shear bolted connections. The load is transfer between the connected members (here denominated as plate) through shearing of the screw. The failure modes that may develop are listed in Table 1. Though, the modes of failure are clearly identified, the behaviour of the screw connections is much more complex because of screw rotation. In single shear plane connections, the eccentricity of the loading leads to a rotation of the screw (tilting) and originates a pull-out force on the screw. This pull-out force is then compensated by the screw head pressure against the steel plate and consequently local bending develops on the plate. The higher the flexibility of the steel plate, the higher the rotation. A model to predict the fastener tilting based on the plate thickness and on the pitch distance is proposed in [20]. In the shear connections with eccentricity, as single shear plane connections, fastener tilting occurs and is coupled with tearing and/or with bearing. In the codes no distinction is made between these modes of failures being identified as a unique mode. Further discussion on the design prescriptions are given below. The shear failure of the screw occurs only in the case thicker plates are used. As in light steel framing, thin elements are often used, this failure mode do not occur so often. In relation to the net section failure, it mainly occurs in the case of connections with thin and narrow plates, for example when using extra plates to connect members. In the majority of the connections in light steel framing, this mode of failure do not occurs as connections are performed often between members directly where the cross-section is considerably resistant in comparison to the resistance of other modes of failure.

Table 1: Failure modes in screw connections subject to shear

Failure Mode Description




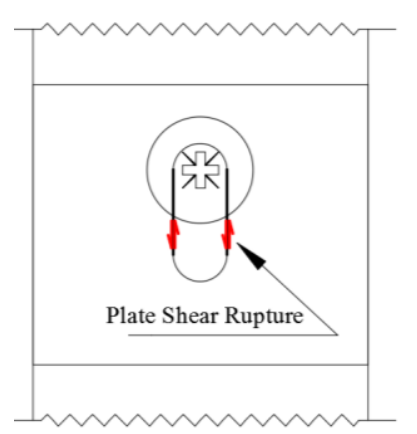

Tilting and Tearing

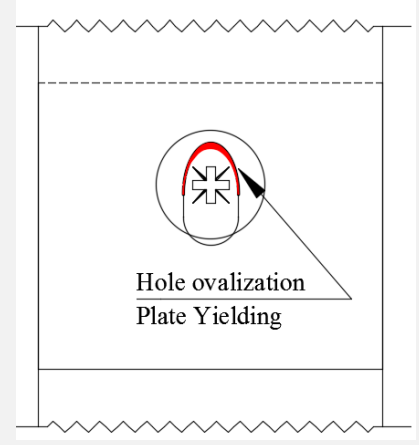

Tilting and Bearing

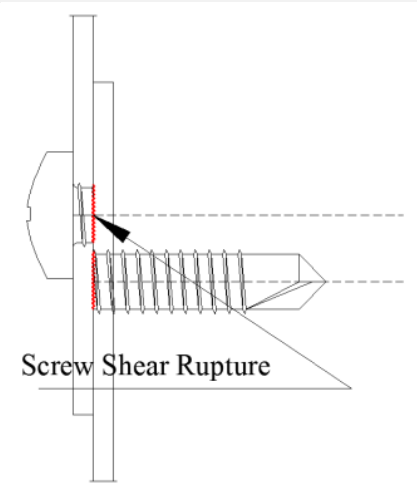

Shear of the screw

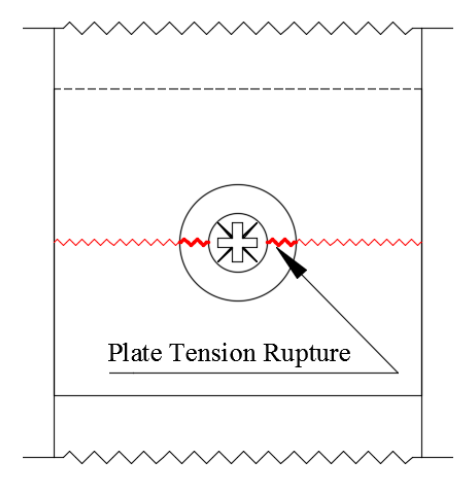

Net-section
Screw rotation occurs combined with plate tearing.

Pure shear deformation and damage of the plate is observed. High elongation of the screw hole is observed.

Screw rotation occurs combined with screw-plate bearing. An elongation of the screw hole is noticed. Yielding of the plate occurs due to the pressure induced by the screw.

The shear resistance of the screw is exceeded and the screw is split in two parts. Failure occurs in the shear plane which corresponds to the connected plates interface.

The resistance of the plate in tension is exceeded due to the reduction of the cross-section. Concentration of stresses occurs around the holes which exceed the yield strength of the material. The failure crack is perpendicular to the loading. 
1 In the construction of panels, the screw connection between the members, vertical and horizontal studs, is

2 often performed inserting the vertical studs ( $\mathrm{C}$ or $\Omega$ shape type) in the horizontal studs (U shape type or $\mathrm{C}$

3 shape type with a notch), as illustrated in Figure 2. This configuration is a shear connection type and failure may occur from one of the modes described in Table 1. In the case of braced panels, this type of connection

5 is also used to connect the diagonal bracings or the OSB boards to the panel members (vertical and

6 horizontal studs). Subsequently, the bearing capacity and the stiffness of the panels to lateral loading depend

7 on the behaviour of this type of connections. Therefore, the characterization of the connection behaviour is important to evaluate the panel performance. In the next sections, the behaviour of shear screw connections

9 in LSF is discussed based on analytical, experimental and numerical investigations.

10

11
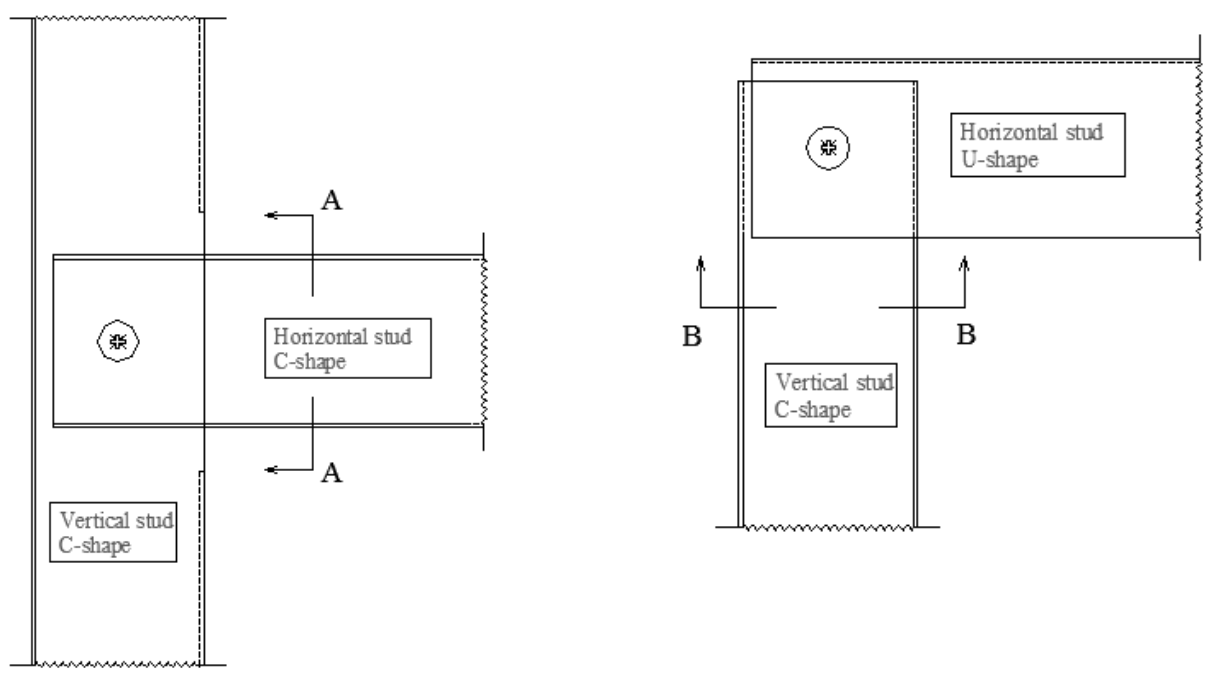

View A-A

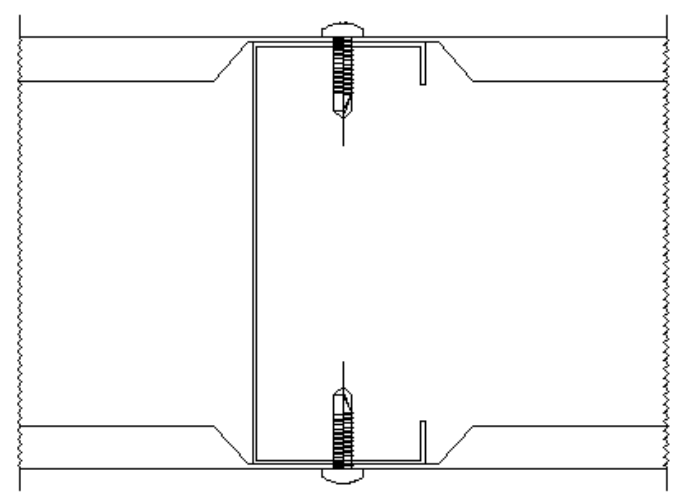

View B - B

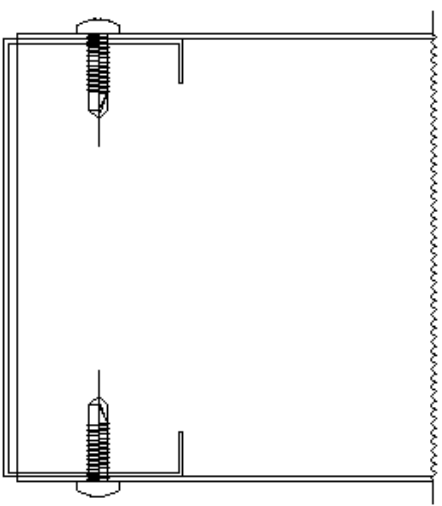

a) Connection within the panel

b) Connection at the edge of the panel

Figure 2: Examples of stud-stud screw connection in LSF panels 


\subsubsection{Assessment of the response of single shear screw connections}

2 The design of a screw connection is based on the evaluation of the individual failure modes listed in Table 1. In practical terms, the principles of the component method [21] are applicable. The connection may be represented by the mechanical spring model illustrated in Figure 3. Each mode of failure is identified as a component and reproduced by a translational spring. The connection response results then from the assembly of four springs in series. In practice, the deformation of such connection is completely neglected and therefore the model is only used to evaluate the load capacity. Table 2 and Table 3 summarize the design expressions to evaluate the resistance of screw connections according to the reference codes for the design of light steel framing structures [16],[17]. The main differences between the design rules reproduced in these tables consist in the evaluation of the bearing and tearing failure. The EN1993-1-3 [16] approach is limited to the cases where the plate near the head of the screw is the thinnest. The other cases are not covered. This is not case in the AISI S100 [17] where all the situations are accounted for. In the latter, different design equations for the same mode of failure are given which are related to the design criterion (ASD - Allowable Strength Design; LRFD - Load and Resistance Factor Design; LSD - Limit State Design). The comparison between the analytical expressions proposed by the two codes, to evaluate these two modes of failures, is illustrated in Figure 4 and Figure 5. In the application of the analytical expressions, the following was considered: single screw, one steel grade, same screw diameter, no influence of edges and variation of plate thickness. Figure 4-a) shows that in case of the EN 1993-1-3 [16], only for higher thickness of the steel plate $t_{l}$, bearing becomes the governing mode. In the case of AISI S100 [17], the governing mode of failure depends on the thickness of both plates, although tearing is only control by the plate not in contact with the head. Figure 4-b) shows that if the thickness of the latter is increased, the bearing of the plate in contact with screw head becomes governing. Figure 5 illustrates a direct comparison between the two methods. Figure 5-a) represents the characteristic resistance and Figure 5-b) represents the design resistance. For the latter, only the ASD is used for the AISI S100 code [17]. For both modes of failure, the characteristic resistances given by the EN 1993-1-3 are smaller than those calculated with AISI S100. Due to the higher safety factor of the AISI S100, this is inverted when design values are computed. 


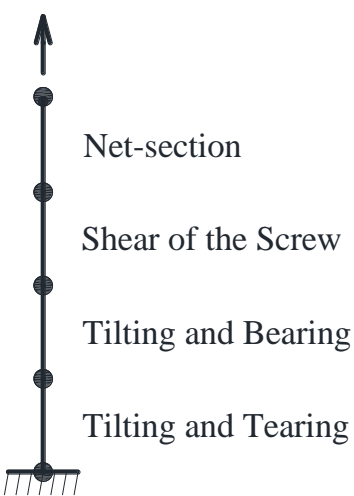

Figure 3: Spring mechanical model reproducing a screw connection

Table 2: Design rules for screw connections according to Eurocode [16]

\begin{tabular}{|c|c|}
\hline Failure Mode & Design rules \\
\hline Tilting and Tearing & $\begin{array}{c}F_{b, R d}=\frac{\alpha f_{u} d t_{1}}{\gamma_{M 2}} \\
\left\{\begin{array}{c}t_{1}=t_{2} \rightarrow \alpha=3.2 \sqrt{t_{1} / d} \leq 2.1 \\
t_{2} \geq 2.5 t_{1} \text { and } t_{1}<1.0 \mathrm{~mm} \rightarrow \alpha=3.2 \sqrt{t_{1} / d} \leq 2.1 \\
t_{2} \geq 2.5 t_{1} \text { and } t_{1} \geq 1.0 \mathrm{~mm} \rightarrow \alpha=2.1 \\
t_{1} \leq t_{2} \leq 2.5 t_{1} \rightarrow \alpha \text { obtained by linear interpolation }\end{array}\right.\end{array}$ \\
\hline Tilting and Bearing & $\begin{array}{l}\text { Where: } t_{l} \text { is thickness of the plate in contact with the screw head; } t_{2} \text { is the thickness of the } \\
\text { plate not in contact with the screw head; } d \text { is the screw nominal diameter; } f_{u} \text { is the ultimate } \\
\text { tensile strength of the steel sheet; } \gamma_{M 2} \text { is the partial safety factor (which the recommended } \\
\text { value is } 1.25 \text { ). }\end{array}$ \\
\hline Shear of the Screw & $\begin{array}{l}\qquad F_{v, R d}=\frac{F_{v, R k}}{\gamma_{M 2}} \\
\text { Where: } F_{v, R k} \text { is the characteristic shear resistance of the screw determined by testing. } \\
\text { In the case deformation capacity is required: } \\
\qquad F_{v, R d} \geq 1,2 F_{b, R d}\end{array}$ \\
\hline Net Section & $\begin{array}{l}\qquad F_{n, R d}=\frac{A_{n e t} f_{u}}{\gamma_{M 2}} \\
\text { Where: } A_{n e t} \text { is the net cross-section area of the plate (accounting for the screw hole). }\end{array}$ \\
\hline Range of validity & $\begin{array}{c}0.45 m m \leq t_{1}, t_{2} \leq 4 m m \\
e_{1} \geq 1.5 d ; e_{2} \geq 1.5 d ; p_{1} \geq 3 d ; p_{2} \geq 3 d ; \\
2.6 m m \leq d \leq 6.4 m m \\
f_{u} \leq 500 \mathrm{~N} / \mathrm{mm}^{2}\end{array}$ \\
\hline
\end{tabular}



contemplated by the code.

Table 3: Design rules for screw connections according to North-American Standard [17].

\section{Failure Mode}

\section{Design rules}

$$
\begin{gathered}
\text { AISI S100 ASD: } F_{b, R d}=\frac{P_{n s}}{\Omega} \\
\text { AISI S100 LRFD: } F_{b, R d}=\Phi P_{n s} \\
\text { AISI S100 LSD: } F_{b, R d}=\Phi P_{n s}
\end{gathered}
$$

$$
\left\{\begin{aligned}
t_{2} / t_{1} \leq 1.0 & \rightarrow P_{n s}=\operatorname{Min}\left(4.2 \sqrt{t_{2}^{3} d} F_{u 2} ; 2.7 t_{1} d F_{u 1} ; 2.7 t_{2} d F_{u 2}\right) \\
t_{2} / t_{1} \geq 2.5 & \rightarrow P_{n s}=\operatorname{Min}\left(2.7 t_{1} d F_{u 1} ; 2.7 t_{2} d F_{u 2}\right) \\
1.0 \leq t_{2} / t_{1} \leq 2.5 & \rightarrow P_{n s} \text { obtained by linear interpolation }
\end{aligned}\right.
$$

Tilting and Tearing

Limitation due to end distance $\left(\mathrm{e}_{1}\right)$

$$
P_{n s} \leq t_{1} e_{1,1} F_{u 1} \text { or } / \text { and } t_{2} e_{1,2} F_{u 2}
$$

Tilting and Bearing

Where: $t_{1}$ is thickness of the plate in contact with the screw head; $t_{2}$ is the thickness of the sheet not in contact with the screw head; $d$ is the screw nominal diameter; $F_{u l}$ is the ultimate tensile strength of the steel plate in contact with screw head; $F_{u 2}$ is the ultimate tensile strength of the steel plate not in contact with screw head; $e_{l, l}$ is the edge distance in direction of the loading of plate in contact with the screw head; $e_{1,2}$ is the edge distance in the direction of the loading of the plate not in contact with screw head; $\Omega$ is the safety factor for ASD (recommended value is 3.00); $\Phi$ is the resistance factor for LRFD and LSD (recommended values are 0.50 and 0.40 , respectively).

$$
\text { AISI S100 ASD: } F_{v, R d}=\frac{P_{S S}}{\Omega}
$$$$
\text { AISI S100 LRFD: } F_{v, R d}=\Phi P_{S S}
$$

Shear of the Screw

$$
\text { AISI S100 LSD: } F_{v, R d}=\Phi P_{S S}
$$

Where: $P_{s s}$ is the shear resistance of the screw determined by testing.

\section{Net Section}

$$
\text { AISI S100 LRFD: } F_{n, R d}=\Phi A_{n} F_{u}
$$


AISI S100 LSD: $F_{n, R d}=\Phi A_{n} F_{u}$

Where: $A_{n}$ is the net cross-section area of the plate (accounting for the screw hole); $\Omega$ is the safety factor for ASD (recommended value is 2.00 ); $\Phi$ is the resistance factor for LRFD and LSD (recommended values are 0.75 .

Range of validity

$$
e_{1} \geq 1.5 d ; e_{2} \geq 1.5 d ; p_{1} \geq 3 d ; p_{2} \geq 3 d
$$

AISI S100: $2.0 \mathrm{~mm} \leq d \leq 6.4 \mathrm{~mm}$

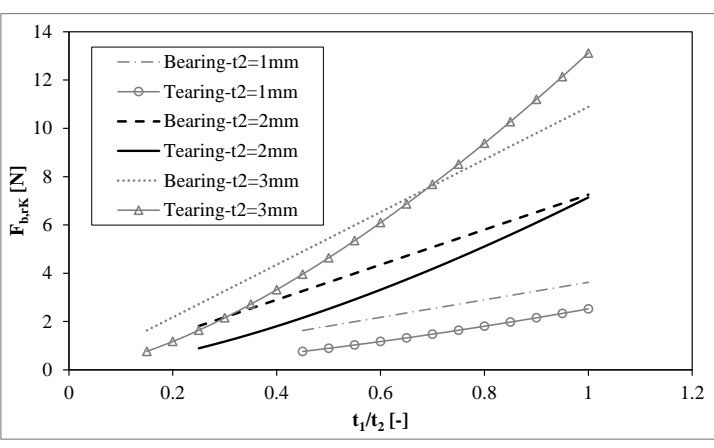

a) $\mathrm{EN} 1993-1-3$

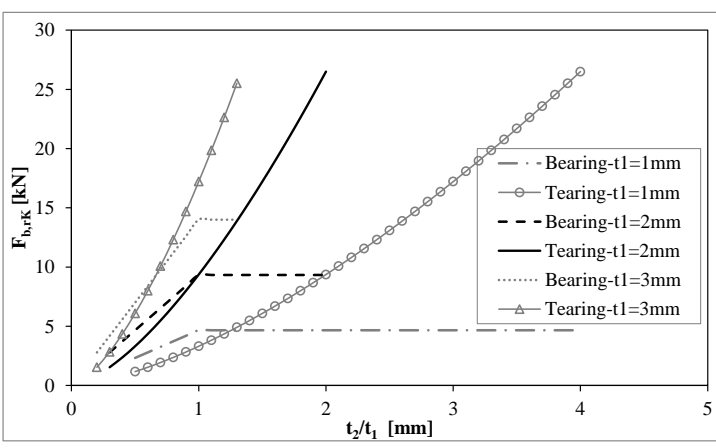

b) AISI S100

Figure 4: Evaluation of Tearing and Bearing failure of screw connection in shear according to the EN 1993-1-3 [16] and the AISI S100 [17] $\left(f_{u}=360 \mathrm{~N} / \mathrm{mm}^{2} ; d=4.8\right)$

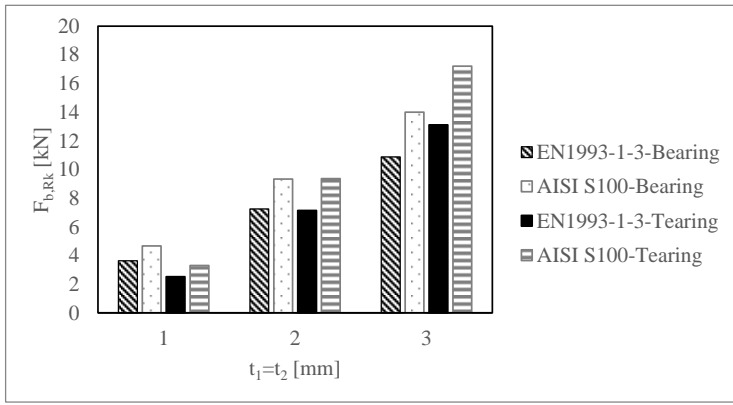

a) Characteristic values

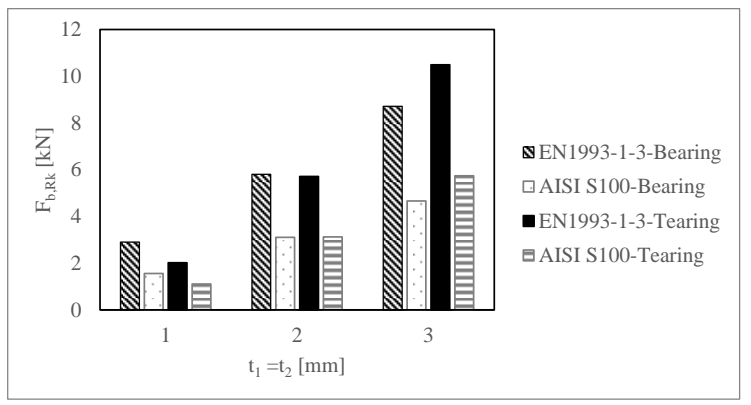

b) Design values

Figure 5: Comparison EN 1993-1-3 [16] and AISI S100 [17] analytical expressions for determination of tearing and bearing resistance

The connection resistance is finally obtained from the assembly of the individual components, which are arranged in series (Figure 3). Accordingly, the following applies:

$$
F_{b}=\operatorname{Min}\left(F_{b, R d} ; F_{v, R d} ; F_{n, R d}\right)
$$

(1)

In the case of connections with multiple screws, in [22] a "group effect" leading was verified to a resistance of the connection not proportional to the number of screws. Hence, the reduction factor in (2) was proposed. 
1 This factor is valid as long as the minimum screws spacing is greater than $3 \mathrm{~d}$, which is independent of the screws pattern. In Figure 6 the reduction factor $(\mathrm{R})$ is plotted in function of the number of screws. It is noted that only for two screws the reduction is approximately $20 \%$. With the increase of the number of screws, this reduction factor tends to approximately 0.65 . The codes [16],[17], totally neglect this "group effect". In the particular case of the connection illustrated in Figure 2, the application of this reduction factor is not clear as the two screws used in the connection are located in different planes.

$$
R=(0.535+0.467 / \sqrt{n}) \leq 1.0
$$

where: $n$ is the number of screws used in the connection.

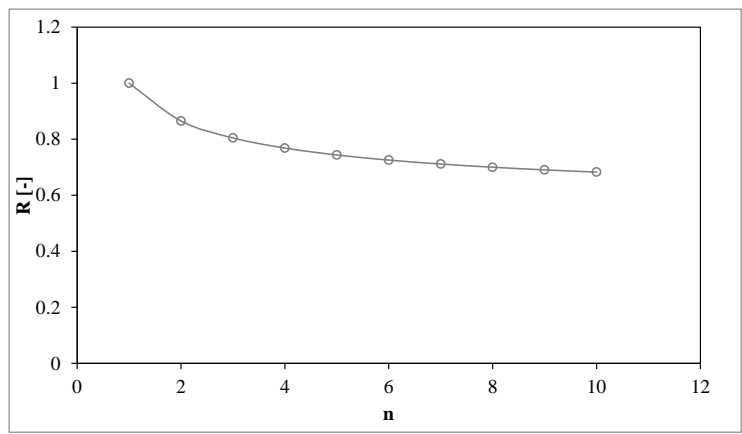

Figure 6: Reduction factor for "group effect" in multiple screw connection [22]

The connection resistance is then calculated by the following expression:

$$
F_{b, t o t a l}=F_{b} n R
$$

In relation to the deformation of the screw connection subjected to shear load, as referred above, it is usually disregarded and consequently, no model is found in the literature.

For the connection illustrated in Figure 2, a perfect align between the screw and the center of gravity of the horizontal profile is unlike. Consequently, there are eccentricities between the loading and the connection. In the connection only one screw (in each side) is used. Accordingly, and assuming that this connection works as a perfect hinge, the axis of rotation is the line defined by the two screws. Using as example the connection in Figure 2-a), the free body rotation $(\theta)$ ends when the profiles come into contact, as represented by the deformed connection in Figure 7 . The equilibrium is then established: the force applied $\left(F_{\text {external }}\right)$ with eccentricity $\left(e_{e x t}\right)$ originates a secondary bending moment, which is balanced by the contact force $\left(F_{\text {contact }}\right)$ developed between the profiles. This contact force has an eccentricity $\left(e_{\text {cont }}\right)$ to the rotation point. The friction forces that may develop between the profile flanges were completely neglected in this model, as this depend on the tightening forces which are very limited in this type of connection. 

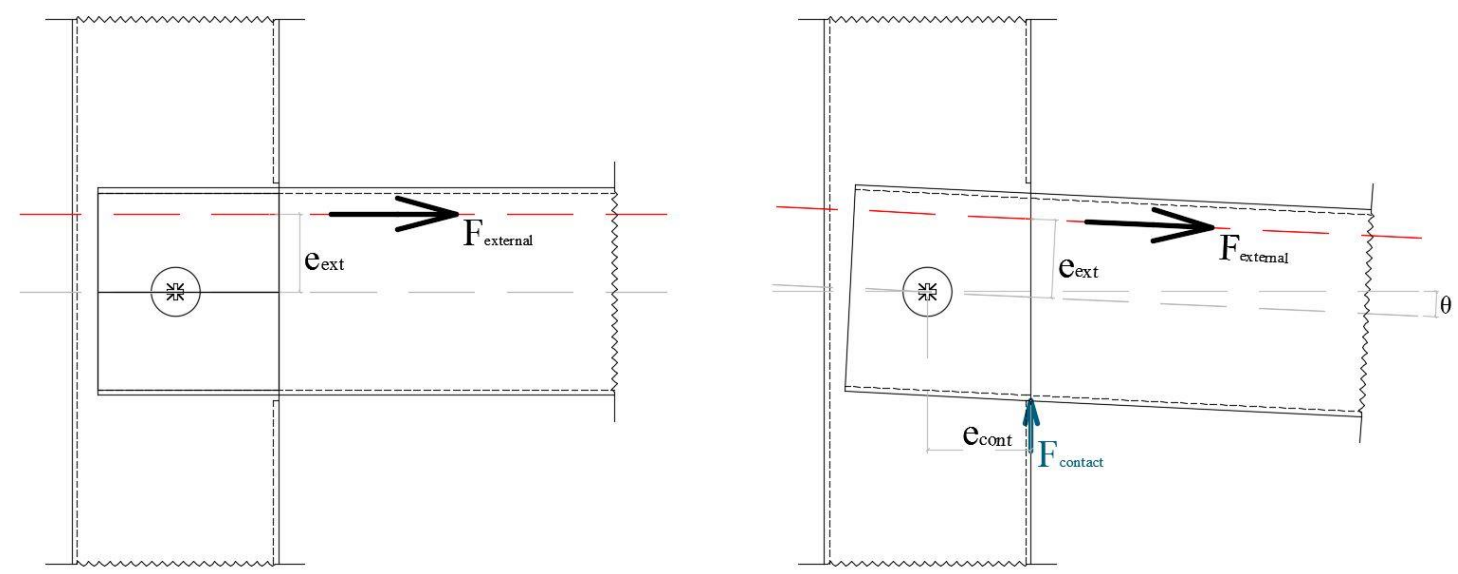

Figure 7: System of forces due to the eccentricity of loading in the screw connection between panel studs (horizontal and vertical).

\section{$4 \quad 2.1 .3 \quad$ Experimental test on single shear screw connections}

\subsubsection{Experimental Programme}

6 The experimental tests performed at the University of Coimbra [23], consist on single shear screw 7 connection with the configuration illustrated in Figure 7. The main objective of these tests was the characterization of the connection behaviour, in particular the determination of the force-displacement curve. In the tested connection, two cold-formed profiles were connected using two self-drilling screws. A channel profile was inserted into a $\mathrm{U}$ profile, as represented in Figure 2-a), and the connection was accomplished by screwing each flange of the $U$ profile to the flanges of the channel profile. This type of connection is very common in the construction of light steel framing panels. Two type of screws were used, which differ on the producer and consequently on the dimensions: Fabory and SFSintec. Table 4 summarizes the experimental programme. A total of 6 tests were conducted, 3 for each type of screw. This was the only variable on the tests. All tests were static monotonic. In order to characterize the material properties of the steel cold-formed profiles, classical coupon tests were also performed.

Table 4: Screw connection test specimens

\begin{tabular}{ccccc}
\hline$N^{0}$ & Test ID & Profiles & Screws & Test Type \\
\hline 1 & FAB T1 & & Fabory® & \\
2 & FAB T2 & C-100x40x10x1 & $\Phi 4,8$ & \\
3 & FAB T3 & U-100x40x1 & & Static Monotonic \\
4 & SFS T1 & both S320GD+Z & SFSintec® & \\
& & & $\Phi 4,2$ & \\
5 & SFS T2 & & & \\
& & &
\end{tabular}


2 The geometry of the screws used in the tests is illustrated in Figure 8. Both screws were self-drilling screws.

3 Besides the differences in the screw nominal diameter and length, the main difference is in the head of the

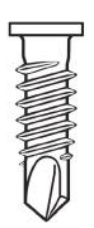

SFSintec $®$ SL3-F $\quad$ Fabory® ST4.8

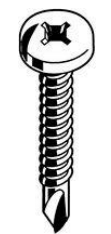
(1) screw. The SFSintec ${ }^{\circledR}$ screw has a square flat head, which has the practical advantage of a reduced head thickness, beneficial for the fixation of non-structural panels to the frame. One the other hand, a special tool is required to its application, but the most important issue is in terms of performance, as the head-plate contact surface is smaller given the reduce dimension of the head. The Fabory ${ }^{\circledR}$ screw is a "classical" selfdrilling screw with a pan head.

Table 5Table 5 provides the geometrical characteristics of each type of screw, depend on the producer. All information on the screws was obtained from the technical documents [24][25]. No experimental tests were performed on the screws. 2 Figure 8: Self-drilling screws used in the screw connections tests

Table 5: Geometrical properties of the self-drilling screws used in the screw connections tests

\begin{tabular}{cccccc}
\hline $\begin{array}{c}\text { Screw } \\
\text { Designation }\end{array}$ & Screw & Head Type & Head & Shaft & Shaft \\
& Self- & Circular pan & diameter & length \\
ST4.8 & drilling & head & $\mathrm{d}=9,5 \mathrm{~mm}$ & $4,8 \mathrm{~mm}$ & $13 \mathrm{~mm}$ \\
& Self- & Square flat head & $\mathrm{b}=6,0 \mathrm{~mm}$ & $4,2 \mathrm{~mm}$ & $15 \mathrm{~mm}$ \\
\hline SL3-F-4.2 & drilling & & & & \\
\hline
\end{tabular}

\subsubsection{Test layout}

The general layout of the test specimens is given in Figure 2-a). The nominal dimensions of the test specimens are given in Figure 9. The tests were performed in a testing press machine. In order to fix the test specimen to the testing machine, additional steel pieces were used, as illustrated in Figure 10 . On the bottom side, the horizontal profile web was bolted to the auxiliary steel plates using 8 bolts. During the test, 
1 these bolts are loaded in tension. On the top side, the web of the vertical profile was connected to the other auxiliary steel plate through a double overlap shear connection using 4 bolts. These auxiliary steel plates

3

4

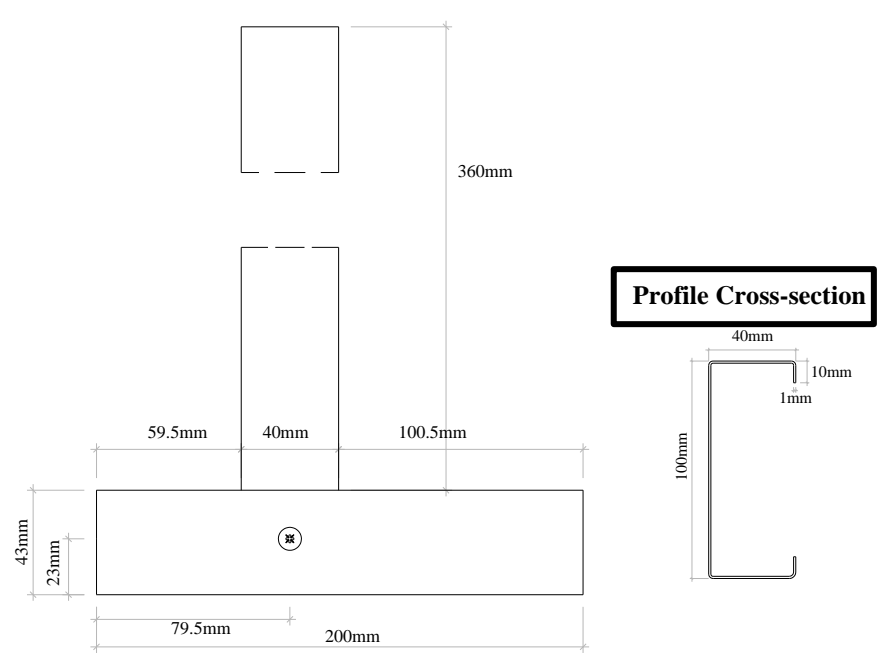

Figure 9: Screw connection test specimens nominal dimensions

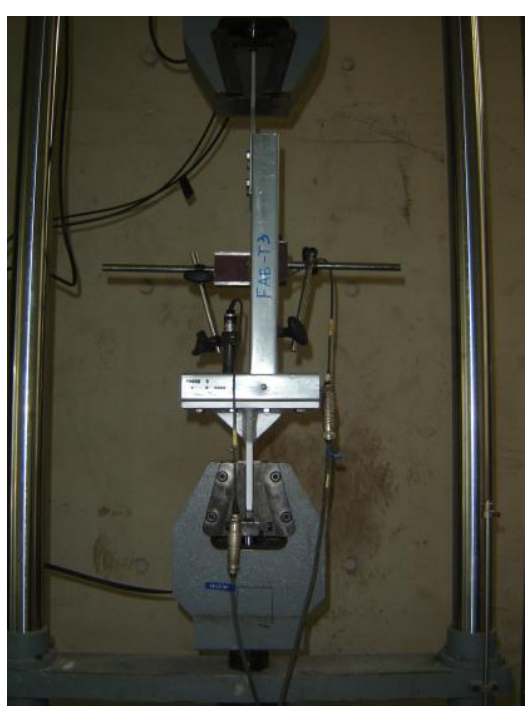

Figure 10: Screw connection test layout

11 The loading of the test specimens was monotonic and consisted of an imposed controlled displacement.

12 The test speed was $0.02 \mathrm{~mm} / \mathrm{s}$ applied up to connection failure. The displacements were measured by

13 LVDT's fixed at both sides of the vertical profile web as illustrated in Figure 11. The loading was controlled by the testing machine. 


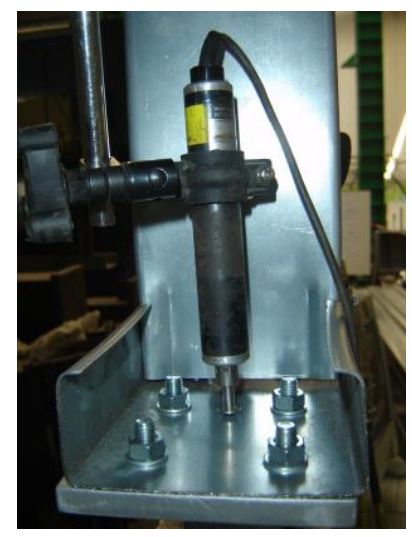

Figure 11: Screw connection LVDT's position

\subsubsection{Analysis and discussion of the test results}

The force-deformation curves obtained from the screw connections tests are represented in Figure 12. The results of test number 4 are not included due to a problem of the fixation system during the test. The designation of LVDT 1 and LVDT 2 is related to the position of the LVDT. LVDT 1 was positioned 'inside' the vertical profile between the flanges and LVDT 2 on the other side of this profile (opposite side of the profile web). The response of the tests is very similar. Only test specimen SFS T2 showed some deviations, especially in what concerns the stiffness. This may be due to installation imperfections. The response is characterized by a force-deformation relation with nonlinearity up to the maximum force, which is governed by the local deformation of the plate in front of the screw (bearing). With the increase of the deformation, the screw rotates (tilting) and the screw heads "penetrates" into the steel plate. This is more evident in the test specimens using screws type SL3-F because of the smaller screw head (see Figure 13). When the maximum load is achieved, the response is very instable. The force-deformation curve shows a "wave" shape, with increase and decrease of resistance, due to the screws threads. When the screw rotates, the force transferred is no longer pure shear, tension is developed. The screw is then pull through the steel plate near the screw head. The decrease of resistance in this "wave" behaviour represents the thread crossing the plates. 


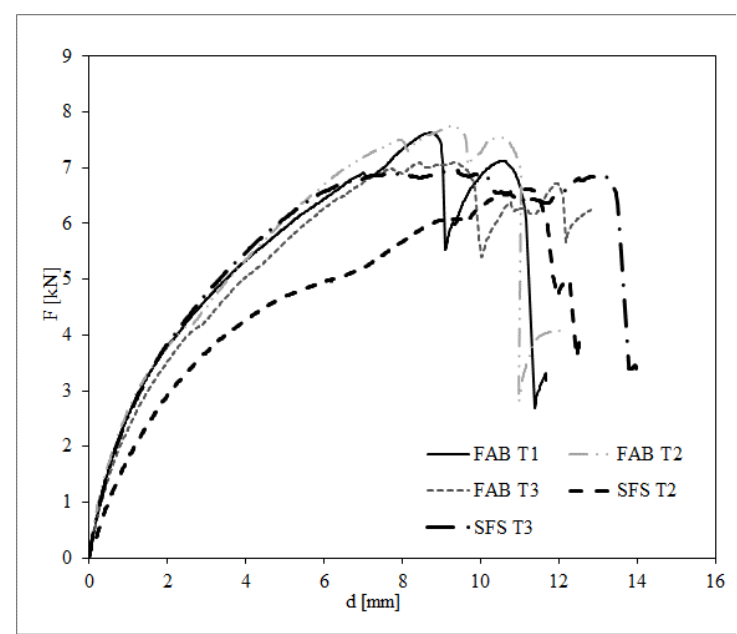

a) LVDT 1

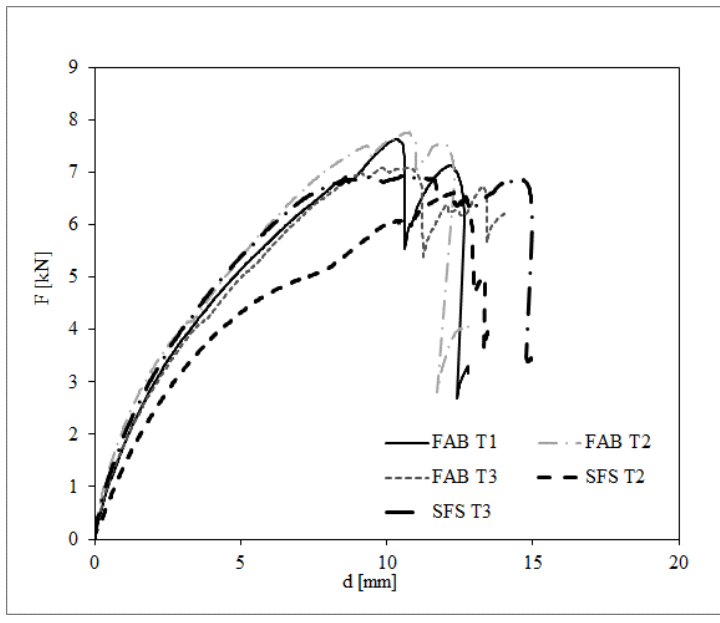

b) LVDT 2

Figure 12: Force-deformation of the screw connection

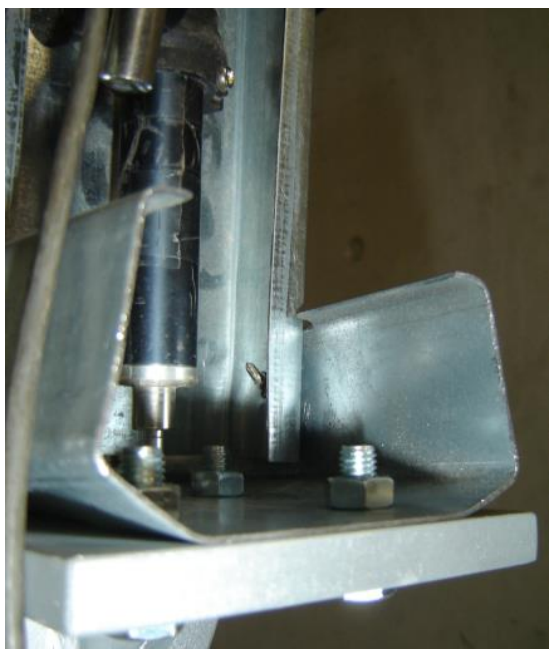

a) SFS SL3-F test

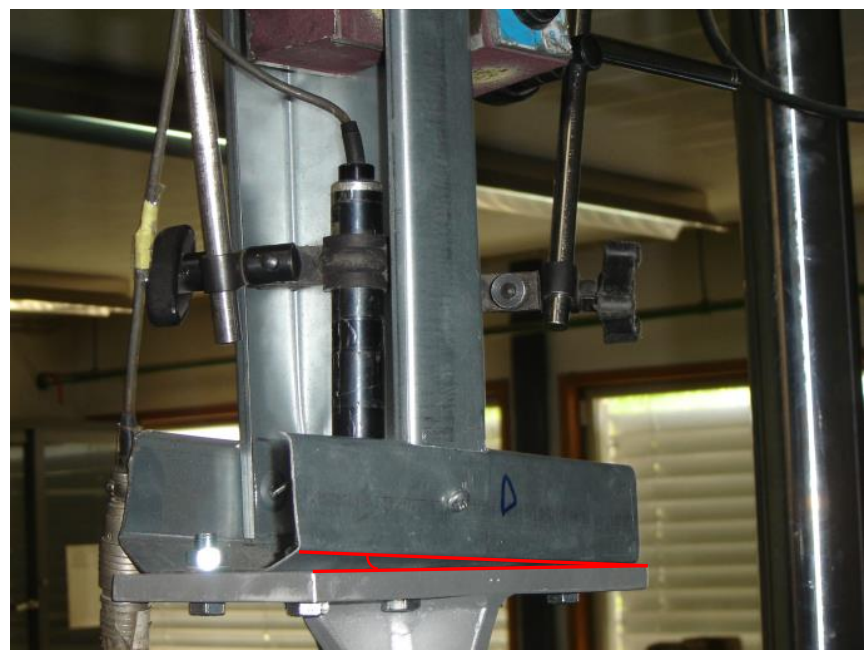

b) ST4.8 test

Figure 13: Screw rotation observed in the screw connection test

In Table 6 are summarized the results of the experimental tests on the steel-to-steel screw connections. The parameters given in the table are the following: $F_{\max }$ - maximum force achieved during the test; $S_{\text {ini }}-$ initial stiffness determined based on the deformation at 2/3 of $F_{\max } ; d_{F m a x}$ - deformation at maximum force; $d_{u}-$ ultimate deformation (deformation at failure of the connection). The average value of each group of tests is also included. A good agreement is obtained in terms of the average maximum resistance and the screw diameter. The ratio (ST4.8/SF3-L) between screw diameters is 1,14 while the ratio between the average maximum resistance is 1,12 . The results show that the connections with FAB screw are slightly stiffer than the connections using SFS screws indicating a direct relation between this parameter and the screw diameter. Subsequently, the connections using SFS screws present higher deformation capacity.

Table 6: Summary of the results of the tests on steel-to-steel screw connections 


\begin{tabular}{ccccc}
\hline Test ID & $\mathrm{F}_{\max }[\mathrm{kN}]$ & $\mathrm{S}_{\text {ini }}[\mathrm{kN} / \mathrm{m}]$ & $\mathrm{d}_{\text {Fmax }}[\mathrm{mm}]$ & $\mathrm{d}_{\mathrm{u}}[\mathrm{mm}]$ \\
\hline FAB T1 & 7,63 & 1407,53 & 8,69 & 11,68 \\
\hline FAB T2 & 7,84 & 1133,77 & 10,64 & 14,03 \\
\hline FAB T3 & 7,12 & 1093,70 & 9,55 & 14,44 \\
\hline Average FAB & 7,53 & 1211,67 & 9,63 & 13,38 \\
\hline SFS T2 & 6,73 & 890,21 & 12,29 & 14,48 \\
\hline SFS T3 & 6,99 & 1273,22 & 10,39 & 14,20 \\
\hline Average SFS & 6,86 & 1081,72 & 11,34 & \\
\hline
\end{tabular}

2 Given the eccentricity of the loading, an additional bending moment develops at the level of the connection

3 which has to be transferred to the horizontal profile through the equilibrium, as illustrated in Figure 7. In

4 this case, the rotation occurs on the horizontal profile flange until contact is achieved. The rotation of the

5 horizontal profile flange was clear in the tests, as it can be observed in Figure 13-b). This rotation was

6 possible due to the plastic deformations that developed in the horizontal profile web around the bolts

7 connecting the horizontal profile to the support plate (see the FEM results).

8 The load applied by the testing machine to the vertical profile had an eccentricity on the connection, as it

9 was applied directly on the web. Consequently, bending moments developed in this profile. In order to

10 quantify the magnitude of this bending moments, the eccentricities considered for the calculation of the additional bending moment on the connection $\left(M_{\text {add,con }}\right)$ and on the profile $\left(M_{\text {add,prof }}\right)$ were $19.5 \mathrm{~mm}$ and $11.54 \mathrm{~mm}$, respectively. The first was obtained from the nominal dimensions of the test specimens and the later results from the calculation of the effective properties of the connection according to [16]. Figure 14 presents the ratio between additional bending moment at the level of the connection $\left(M_{\text {add,con }}\right)$ and on the profile $\left(M_{a d d, p r o f}\right)$ and the resistant bending moment $\left(M_{R d, p r o f}\right)$, determined according to [16]. As the response of all specimens were similar, only the result of $F A B T 2$ was used in this calculation. The additional bending moment at the level of the connection and on the profile represents approximately $40 \%$ and $25 \%$ of the resistance bending moment capacity, respectively. The screws work as axis of rotation. The bending moment developed at the level of the connection is in equilibrium with the contact force that occurs between the profiles, after the rotation of the horizontal profile flange. Figure 15 represents the ratio between the screw connection resistance estimated according to the design codes [16],[17] and the test results. In the computation of the ratio, the characteristic values of the resistance 
were used. According to the model described in the previous section, and based on the configuration of the connection, tearing/tilting is the governing mode of failure. The reduction factor $R$ for the group effect was

$$
F_{b, t e s t}^{\prime}=F_{b, t e s t}(1-\operatorname{Sen} \theta)
$$

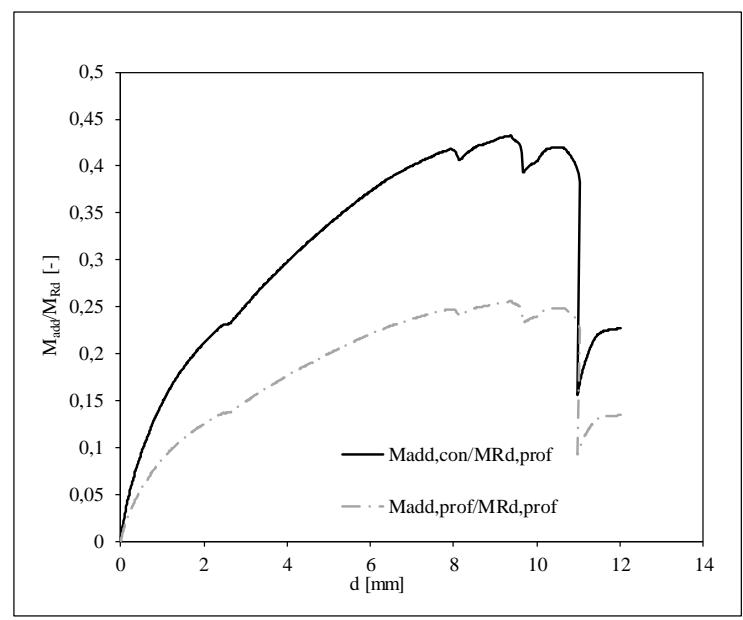

Figure 14: Additional bending moment generated by the eccentricity of the loading on the screw connection tests

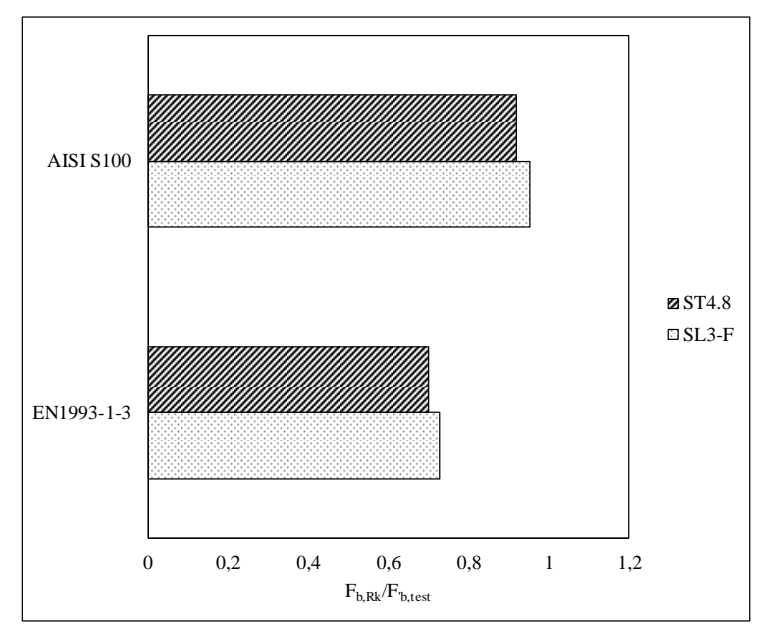

Figure 15: Ratio between screw connection resistance and test result

\subsubsection{Numerical modelling of single shear screw connections}

\subsubsection{Development of FE model for simulation of screw connections in shear}

A numerical model to reproduce the screw connection tests discussed in 2.1.3 was developed using the finite element software ABAQUS [26]. Given the nature of the problem to be simulated, three-dimensional solid elements were used for the modelling of both profiles and screws (Figure 16). Amongst the finite elements available in the ABAQUS library, the continuum stress/displacement 3D solid element C3D8R was chosen. This is a first order 3D solid element with reduced integration. The reason for the selection of this element was the computational efficiency (computation time $v s$ accuracy) obtained in the simulation of similar problems [27]. The analysis considered the geometrical and material nonlinearities. For sake of 


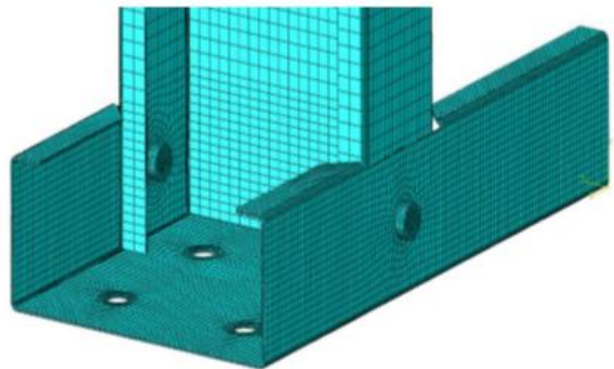

a) General detail of the connection
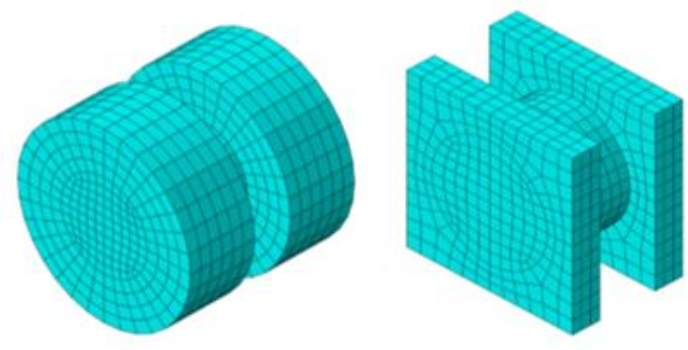

b) Detail of the screws FE model

Figure 16: FE model of the screw connection tested

One of the critical issues on the modelling of such type of connections is the screw-plate (bolt-plate) interaction. The contact between these two parts is normally the source of many numerical convergence problems. The solution to address the interaction in the present case consisted in the use of the "hard" contact model with frictionless behaviour. In this model, the contact between the two parts occurs with transmission of pressure, without penetration and without development of friction forces. The same model was used in the past [27] in similar problems leading to sufficiently accurate results. This interaction model was also used for the contact between steel profiles.

In relation to the boundary conditions and loading strategy, the numerical model simulated the test conditions as much as possible. Supports were applied on the horizontal profile fully restraining the nodes that were in contact with the bolt nut of the fixation system (see Figure 13-a). The loading was applied on the top of the vertical profile until the failure of the connection. In order to obtain the same eccentricity as in the experimental tests, the load was applied only on the web of the profile.

\subsubsection{Validation and calibration of FE model}

For the validation of the numerical model the force-deformation curves and the deformation patterns from the numerical analysis and from the tests were compared. Figure 17 presents the force-deformation curves 
1 for both types of screws. The deformation on the numerical model was determined using the nodal

2 displacements between the nodes representing the fixation point of the LDVT and the edge of the LVDT

3 on the horizontal profile. Due to the simplifications referred in 2.1.4.1, the target of the numerical simulation

4 of the connection was the approximation of the force-deformation behaviour up to the maximum load. As

5 it can be observed, this goal was successfully achieved in both cases. The small deviations between the numerical and the experimental results are mainly due to the imperfections on the test specimens, which were not implemented in the numerical models.

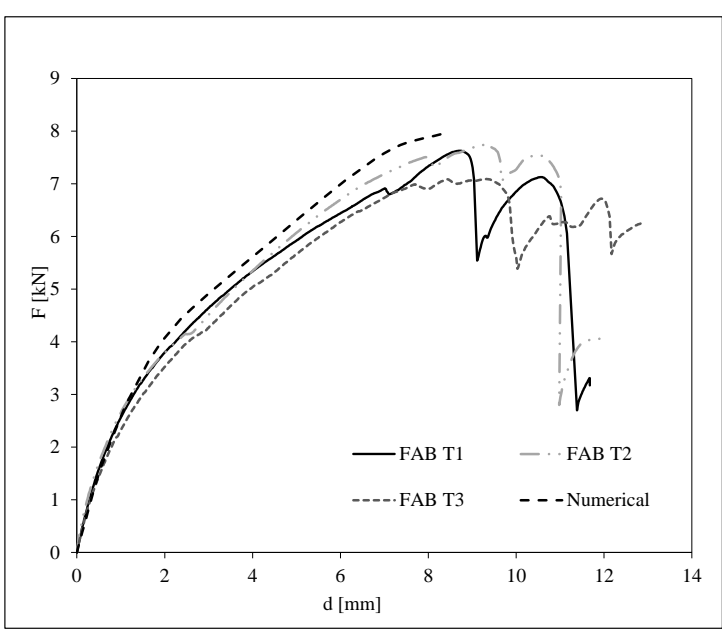

a) Connections using ST4.8 screws

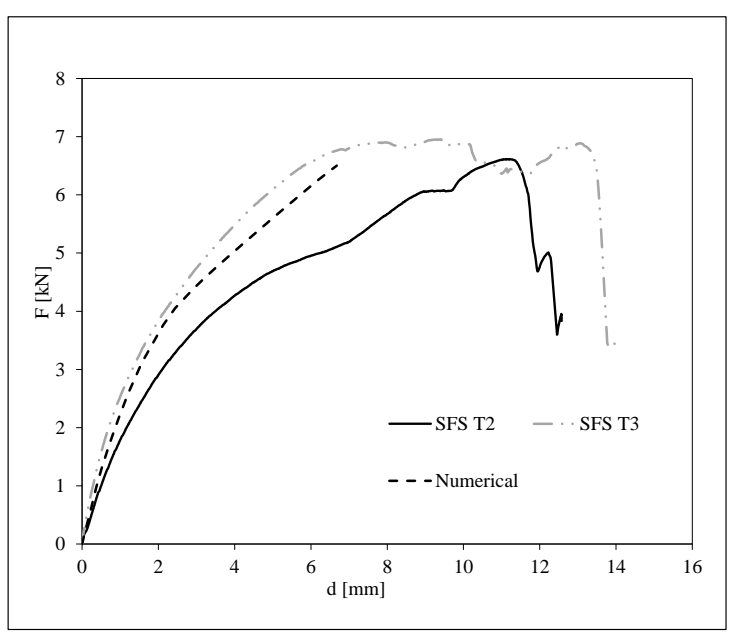

b) Connections using SL3-F-4.2 screws

Figure 17: Comparison between the force-deformation curves of the numerical model and screw connection tests

In order to accomplish a more complete validation of the numerical model, the deformation patterns are compared in Figure 18. Except for the screw rotation, which becomes more evident after the first peak on the force-deformation, a very good reproduction of the test was obtained. The pattern and the amplitude of the deformation are similar. The accuracy of the model is further demonstrated in Figure 19 through the comparison of the yield lines developed in the horizontal profile. These plastic deformations had a significant impact in the measured deformation. 

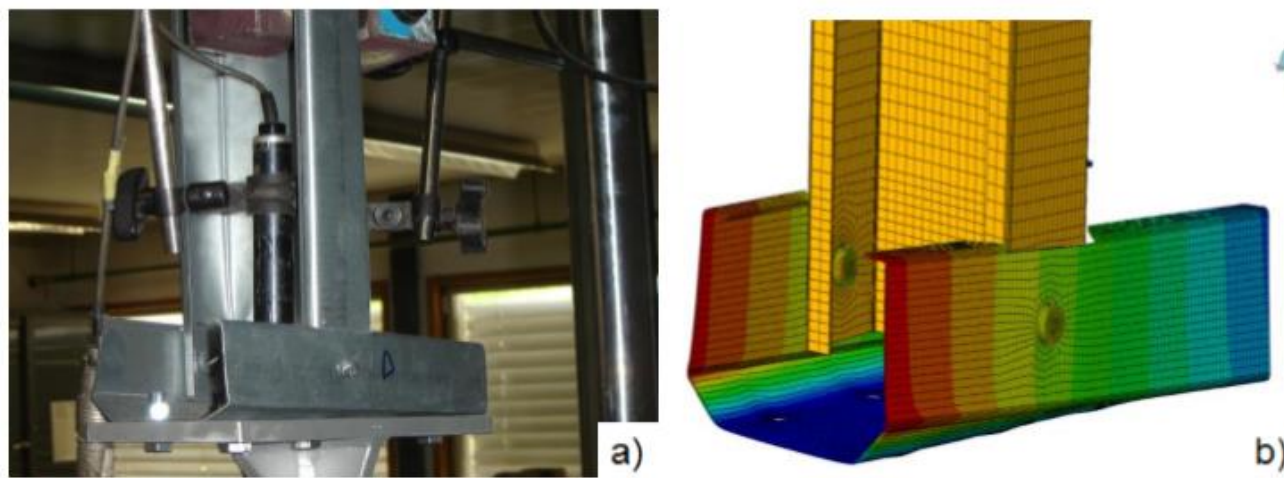

Figure 18: Comparison between the deformation pattern of the screw connection test and numerical model.
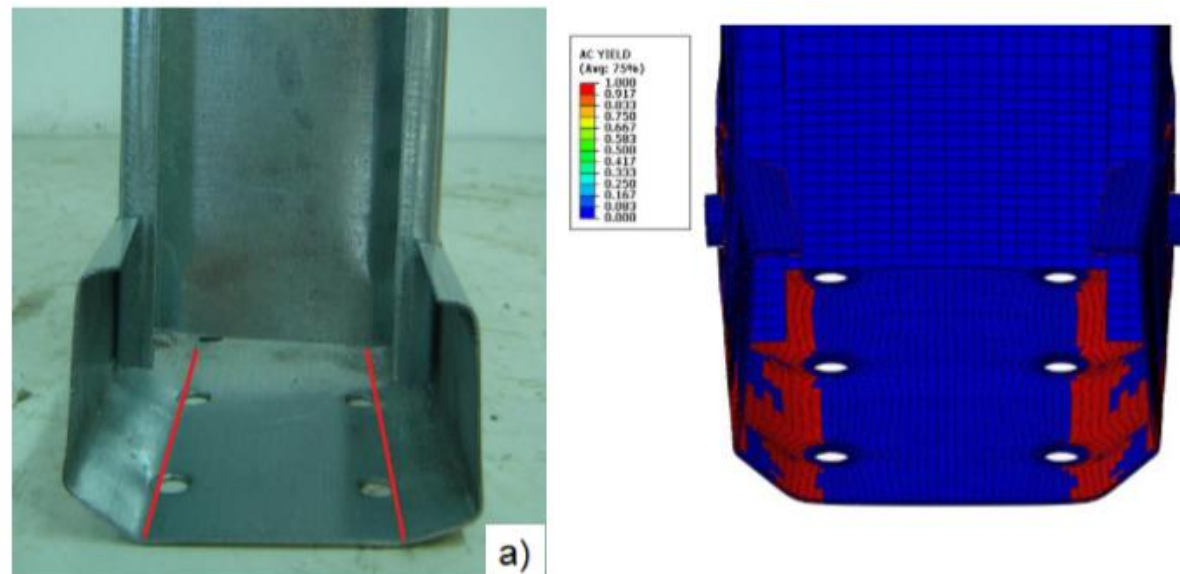

a)

b)

Figure 19: Comparison of the yield lines developed in horizontal profile both in the screw connection test and in the numerical model

\subsubsection{Discussion of the FE model results}

The force-deformation curves presented in Figure 13 represent the total deformation of the test configuration including the plastic deformations developed on the horizontal profile. Thereby, the deformation presented in these charts is not representative of the connection deformation. From the experimental tests, the extraction of the pure connection deformation is not possible. Making use of the validated numerical model, the deformation of the screw connection was predicted. Thus, it was assumed that the connection deformation corresponds to the local deformation within the vicinity of the connection. Figure 20 illustrates the position of the nodes from which the connection deformation was computed. N1 is positioned at the axis of the connection and $\mathrm{N} 2$ is at a distance of approximately $3 \mathrm{~d}$. The value $3 \mathrm{~d}$ was chosen as it defines the limit of the area affected by stresses transferred from the screw to the plates. This limit is given [16] as the minimum distance between the screws, the screw and the edge, and between the screw and end of the plate. The results of the numerical analysis of the connection together with the 
1 experimental results are plotted in Figure 21. It is evident that the behaviour of the connection is very stiff.

2 The deformation becomes relevant only after the profile flanges attained yielding due to the pressure 3 between screw and plate (bearing), as illustrated in Figure 22-a). This figure shows the elements actively

4 yielding at a final stage of the simulation. Figure 22-b) shows the stresses on the screw. It can be observed 5 the higher values on the screw shaft, due to the screw-flanges bearing, and that the stresses on the "screw 6 heads" are not symmetric. The latter indicates the rotation of the screw as observed in the experimental 7 tests. However, due to the simplifications considered in the model of the screw, the numerical model cannot reproduce the post-peak behaviour and the considerable rotation of the screws.

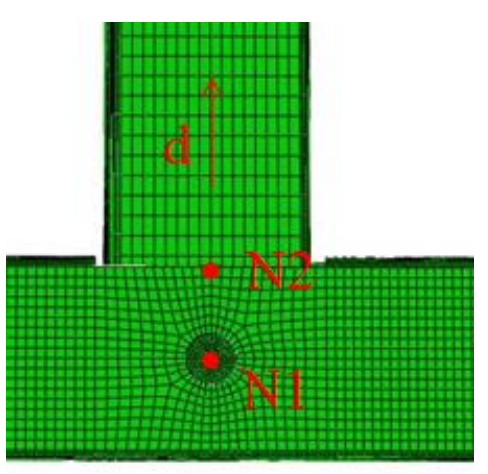

Figure 20: Identification of the nodes for computation of the connection deformation

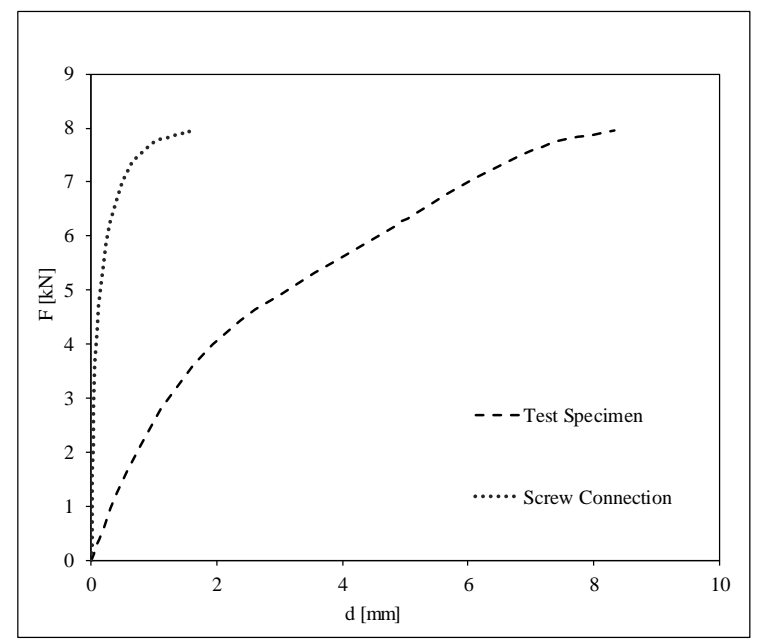

Figure 21: Comparison of the force-deformation curve between connection and global test configuration

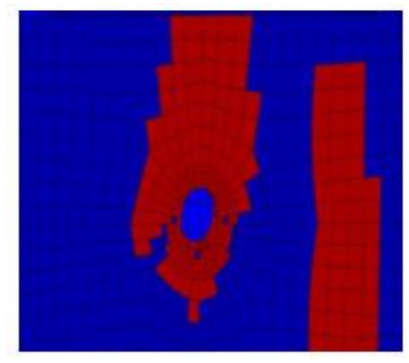

a) Elements actively yielding

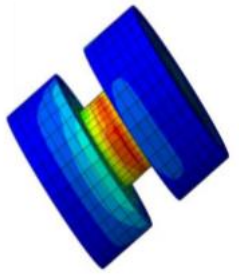

b) Von-Misses stresses distribution on a screw

Figure 22: Detail results of the screw connection FE simulation 
$2 \quad 2.2 .1 \quad \underline{\text { General }}$

3 The contribution of the OSB boards to the lateral stiffness of the steel frame is dependent on the connection between the OSB board and the frame. For the steel frame, self-drilling screws are widely used in these connections because of their efficiency. The behaviour of screw connections between OSB boards and steel frames is not covered by the EN 1993-1-3 [16]. This code disregards completely the contribution of the OSB board, or other non-steel material, to the frame stiffness and resistance to lateral loading. The resistance of these connections has then to be assessed using the EN 1995-1-1 [18]. On the other hand the North American standard [28] takes into account the contribution of these non-steel components to the lateral behaviour of LSF structures. The approaches available in these standards, for the evaluation of the OSB-Steel connections, are hereafter presented and discussed; however, emphasis is given to the European standard. Nevertheless, in general, there is still a lack of information on such type of connections. Thus, experimental tests on OSB-to-steel connections were conducted [29] and the results of these tests are analysed in section 2.2.3.

\subsubsection{Assessment of the resistance of a OSB-to-Steel screw connection}

The load transfer mechanism in a single shear screw connection between a OSB board and a steel profile is similar to the mechanism discussed in section 2.1. The load is transferred from the OSB board to the steel plate through the screw shank in shear, as illustrated in Figure 23. The difference is that now one of the "plates" is made of wood, or wood derived. As referred above, Eurocode 3 [16] does not address this connection or any other issue related to a non-steel material. Consequently, the engineer has to make use of the Eurocode 5 [18] where these type of connections are addressed. Accordingly, the evaluation of the connection is similar to the approach for steel-to-steel connection described above. The connection resistance has to take into account the different modes of failures: on the OSB board, on the screw and on the steel plate. The latter has been described before. Therefore, hereafter only the resistance associated to 


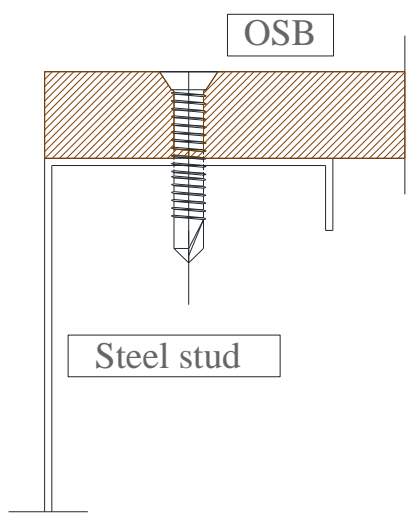

Figure 23: OSB-to-Steel screw connection

3 The referred code makes first a difference between thin and thick plates. Thin plates are those which the 4 thickness is smaller or equal to $0,5 \mathrm{~d}$, where $d$ is the diameter of the screw. Thick plates are those which the thickness is greater than $d$. For intermediate values, a linear interpolation should be used for calculation of

6 the characteristic capacity of the connection. Given that in the present investigation only thin plates are considered, the approach for thick plates is not further addressed. Then, as only single shear connections are used, the characteristic load-carrying capacity $\left(F_{v, R k}\right)$ for the screwed connection is given by:

$$
F_{v, R k, \text { wood }}=\min \left\{\begin{array}{c}
0,4 f_{h, k} t_{1} d \\
1,15 \sqrt{2 M_{y, R k} f_{h, k} d}+\frac{F_{a x, R k}}{4}
\end{array}\right.
$$

9 where: $f_{h, K}$ is the characteristic embedment strength in the OSB board; $t_{l}$ is the thickness of the OSB board; $d$ is the diameter of the screw (nominal diameter); $M_{y, \mathrm{RK}}$ is the characteristic screw yield moment; and $F_{a x, R K}$

11 is the characteristic withdrawal capacity of the screw.

For the determination of the characteristic embedment strength $\left(f_{h, k}\right)$ the following expression applies:

$$
f_{h, K}=65 d^{-0,7} t_{1}^{0,1}
$$

13 The first term in equation (5) is purely related to the OSB board and represents the bearing resistance for the OSB-screw contact. The second term incorporates also the screw response. It considers the bending capacity of the screw and the pull out resistance of the screw. The bending capacity is function of the screw diameter and steel grade, as expressed in (7). A minimum tensile strength of $600 \mathrm{~N} / \mathrm{mm}^{2}$ is required by the code [18]. Then the pull-out component is determined by the minimum of the resistance to pull-out at the head and at the point side of the screw, as expressed in (8).

$$
\begin{gathered}
M_{y, R k}=0,3 f_{u} d^{2,6} \\
F_{a x, R k}=\operatorname{Min}\left\{\begin{array}{l}
f_{\text {ax,k }} d t_{\text {pen }} \\
f_{\text {head }, k} d_{h}^{2}
\end{array}\right.
\end{gathered}
$$




$$
F_{v, R k}=\min \left(F_{v, R k, \text { wood }} ; F_{v, R K, \text { screw }} ; F_{b, R k} ; F_{n, R k}\right)
$$

9 In relation to the American standard [28], the resistance of such type of connections is considered for the

where: $f_{a x, k}$ is the characteristic point-side withdrawal strength; $f_{\text {head, },}$ is the characteristic head-side pull-out strength; $t_{p e n}$ is the point-side penetration length or the length of the threaded part in the point-side member. As in the configuration illustrated in Figure 23, on the point-side of the screw the connection has a steel plate, this resistance may be neglected, as this is only critical in the case this part of the connection is made of timber. Consequently, the shear resistance of the connection is finally obtained by expression (9) and it is defined by the minimum resistance amongst the following modes of failures: wood-screw bearing $\left(F_{v, R k, \text { wood }}\right)$, shear failure of the screw $\left(F_{v, R k, \text { screw }}\right)$, screw-steel bearing $\left(F_{b, R k}\right)$ and steel net-section $\left(F_{n, R k}\right)$. For the resistances related to the screw and steel plate (see Table 2). design of cold-formed steel structures subject to lateral loads. However, the approach is not based on the determination of the resistance of the screw connection but on the overall configuration of the panel. Nominal strengths for diaphragms made of timber are given based on the panel configuration and imposing maximum screw spacing and size of the screws. The prequalified connections between the timber panel and the steel frame are not addressed in this paper. However, further information may be found in [28]. Finally, it should be observed that in both approaches, the minimum edge distance has to be respected. In the next section, the estimation of the connection resistance according to the European code is compared with the results of experimental tests.

\subsubsection{Experimental behaviour on single shear screw connections}

\subsubsection{Test programme and layout}

The experimental tests performed at the University of Coimbra [29], consisted on single shear screw connection between OSB boards and steel plates. The connection between both materials was performed using a self-drilling screw type ST 4.8, as the one used in the steel-to-steel connection described before. The main objective of these tests was the characterization of the connection behaviour, in particular the attainment of the force-displacement curve. A total of five tests were executed. Within the five tests, no variations were performed on the geometrical and material properties. The test specimen's geometry is illustrated in Figure 24 and the main characteristics are summarized in Table 7. The tests were performed in a testing press machine as shown in Figure 25. The test specimens were loaded up to the failure. 


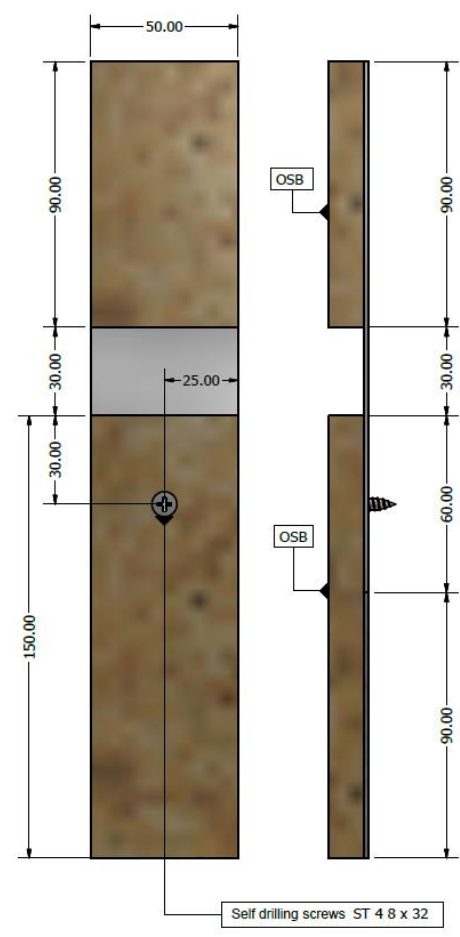

Figure 24: Test configuration of the OSB-steel screw connection

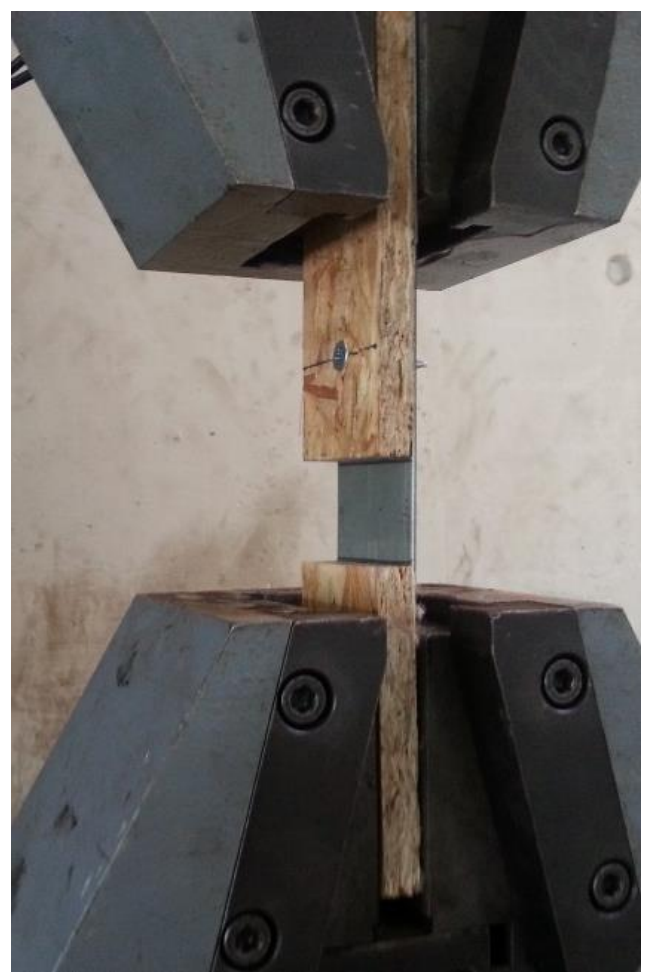

Figure 25: Test layout

Table 7: Main properties of the test specimens of the OSB-steel screw connection

\begin{tabular}{cccc}
\hline Steel Plate & OSB & Screw & Edge distances \\
\hline $\mathrm{t}=1,5 \mathrm{~mm}$ & $\mathrm{t}=12 \mathrm{~mm}$ & $\mathrm{~d}=4,8 \mathrm{~mm}$ & $\mathrm{e}_{1}=30 \mathrm{~mm}$ \\
Steel S280GD+Z & OSB3 & $\mathrm{d}_{\mathrm{h}}=9,5 \mathrm{~mm}$ & $\mathrm{e}_{2}=25 \mathrm{~mm}$ \\
& & ST 4.8 &
\end{tabular}

$\mathrm{d}_{\mathrm{h}}-$ diameter of the head of the screw

3

\subsubsection{Test results}

Similarly to the steel-to-steel connection, this connection showed significant screw rotation, as illustrated in Figure 26. The load-displacement curve is characterized by a significant non-linear response from the beginning of loading. Figure 27 shows the curves for the five test specimens. These curves show a very similar response, which is consistent with the fact that no variations were performed. Consequently, these curves are assumed to represent this type of connection with confidence. Table 8 summarizes the test results using the same parameters used in the analysis of steel-to-steel screw connections (Table 6). The average maximum load observed was 2,5 kN. In Figure 27 the analytical resistance obtained from the application of the method described in section 2.2.2 is included. The analytical resistance is approximately four times smaller than the average resistance of the experimental results. In the analytical calculation the wood 
1 component governs the resistance of the connection. This was also observed experimentally. The reason

2 for the considerable conservative result from the code relies on the fact that wood is a material which has a

3 great variability on its properties.

4

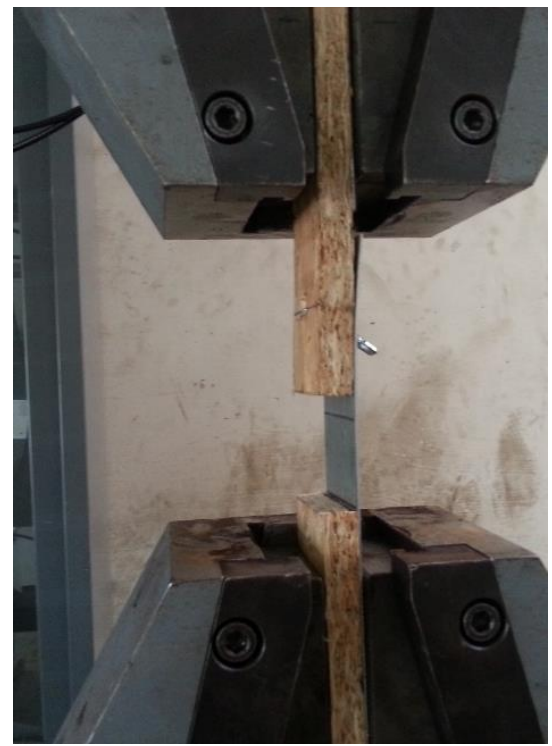

Figure 26: Experimental deformation of the OSB-to-steel screw connection

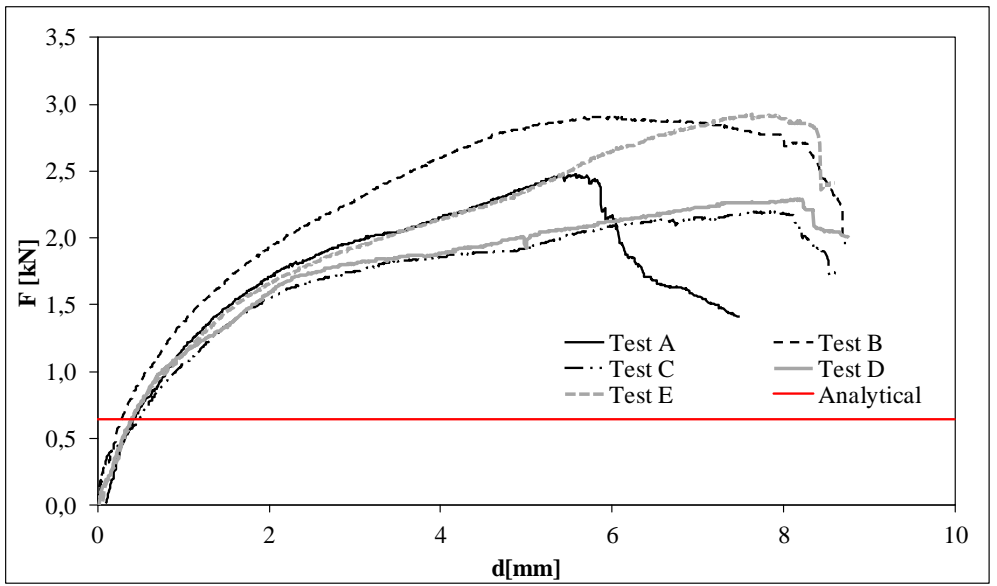

\begin{tabular}{cccccc} 
& Test A & Test B & Test C & Test D & Test E \\
\hline $\mathrm{F}[\mathrm{kN}]$ & 2,44 & 2,90 & 2,19 & 2,29 & 2,93 \\
\hline $\mathrm{S}_{\text {ini }}[\mathrm{kN} / \mathrm{m}]$ & 893,77 & 947,71 & 829,55 & 820,79 & 626,07 \\
\hline $\mathrm{d}_{\text {Fmax }}[\mathrm{mm}]$ & 5,80 & 5,68 & 7,79 & 8,13 & 7,63 \\
\hline $\mathrm{d}_{\mathrm{u}}[\mathrm{mm}]$ & 7,49 & 8,73 & 8,63 & 8,76 & 8,6
\end{tabular}

Figure 27: Experimental force-deformation curve of the OSB-steel screw connection

Table 8: Summary of the experimental test results on the OSB-steel screw connection 


\section{3. Analytical determination of the response of LSF wall panels to lateral loading}

$2 \quad 3.1$ General

3 In what regards the design of LSF walls subjected to lateral loading, the approach of European code and the approach of American code are clearly distinct and reflect the different mentality towards this type of construction in both continents. In the latter, a standard is entirely dedicated to the design of LSF walls subjected to lateral loading [30]. In Europe, although in the past decades different authors have dedicated their research interests to the subject, e.g. [31][32][33], no specific approach is provided by EN 1993-1-3 [16]. Thus, in order to design a LSF structure subjected to lateral loading, the designer has to refer to different design prescriptions from the different structural Eurocodes as EN 1993-1-3 [16], EN 1992-4 [34], EN 1995-1 [18] and EN 1998-1 [35], and establish a design procedure making the link between the different codes. Furthermore, the use of non-steel materials in LSF construction is completely neglected which is not understandable. In the particular case of housing, LSF construction implies the use of non-steel material that have a strong influence on the structure behaviour to lateral loading, e.g OSB or Plywood boards. The lateral stability of LSF structures may be assured using different type of systems such as: diagonal steel straps, LSF vertical trusses, steel sheets and non-steel sheets or panels (e.g. OSB, Plywood, Gypsum board). The use of diagonal steel straps and/or wooden panels, as OSB boards, are amongst the most common solutions and are the subject of the present paper. Therefore, in the following sub-sections the design approach for both type of systems is presented and discussed.

\subsection{LSF walls braced with steel straps}

In LSF walls braced with steel straps, the resistance and stiffness to lateral loads is entirely provided by steel elements. Accordingly, the design approach for this structural systems is commonly denominated "all steel" design approach. This type of systems is entirely covered by the EN 1993-1-3 [16], except for the anchoring to the concrete foundation [34], and complemented by the design prescriptions for the seismic situation [35]. On the other hand, as previously referred, the American code [30] has a standard specially dedicated to the design of LSF structures to lateral load which complements the general design rules for the design of LSF structures given in AISI S100 [17]. The approach of the American standard is a direct design approach based on prescribed design solutions for the different design situations. Nevertheless, the principles behind the design in both codes have the same theoretical base. 
1 The load capacity of a LSF wall subjected to a lateral load results from the bearing capacity of two groups of components: the members and the connections. Figure 28-a) illustrates the different parts of a LSF wall

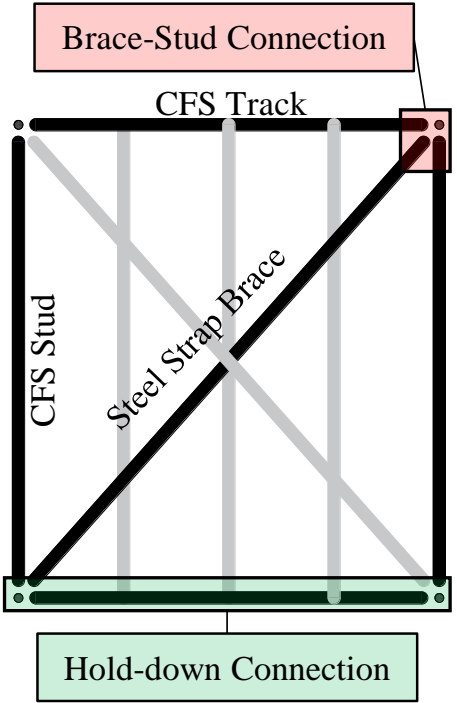

a) Identification of components

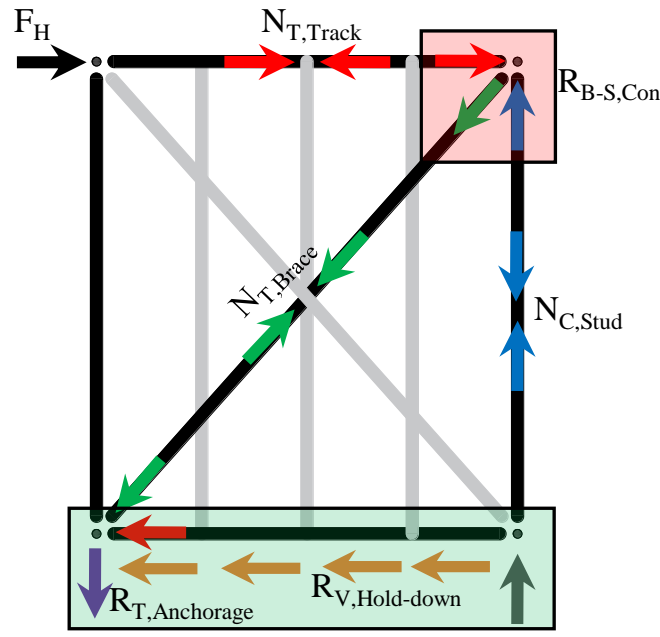

b) Load path

Figure 28: LSF walls braced with steel straps

The design of the above list of components is covered in both codes [16][17]. The load capacity of the wall subjected to lateral loading is given by the smallest resistance of the listed components, where there is equilibrium between the external and internal forces, as expressed by (10).

$$
F_{H, \text { max }} \leftrightarrow \operatorname{Min}\left(N_{C, \text { Stud }} ; N_{T, \text { Track }} ; N_{T, \text { Brace }} ; R_{B-S, \text { Con }} ; R_{T, \text { Anchorage }} ; R_{V, \text { Hold-down }}\right)
$$


1 This approach was addressed in detail by [36] and verified against experimental tests by [37][38], showing

In this model, the slip between wall and foundation may be neglected. The contribution of these components to the initial lateral stiffness of the wall consist in a system of elastic springs in series and may be estimated by expression (11). The detailed evaluation of the initial stiffness of each component is given in [36]. Note that these are determined for the horizontal direction. $K_{\text {ini,H,Wall }}=$

$\frac{1}{\frac{1}{K_{T, \text { Brace }}}+\frac{1}{K_{B-S, \text { Con }}}+\frac{1}{K_{T, \text { Anchorage }}}}$

\subsection{Sheathed LFS walls}

- Diagonal steel strap in tension $\left(\mathrm{K}_{\mathrm{T}, \mathrm{Brace}}\right)$;

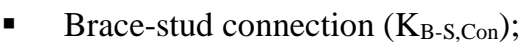

- Wall overturning [governed by the deformation of the anchorage in tension] (KT,Anchorage).

As previously referred, EN 1993-1-3 [16] disregards the contribution of non-steel sheets or panels to the lateral stability of LSF structural walls. However, it has been demonstrated [10] that when these non-steel 
- Wall stud in compression (NC,Stud);

- Wall track in tension $\left(\mathrm{N}_{\mathrm{T}, \text { Track }}\right)$;

- Non-steel sheet or panel in shear ( $\left.\mathrm{V}_{\text {Sheet }}\right)$;

- Sheet-to-Track Connection (R-T,Con);

- Sheet-to-Stud Connection (Rs-s,Con);

- Hold-down connection to the ground $\left(\mathrm{R}_{\mathrm{T}, \text { Anchorage }}\right.$ and $\left.\mathrm{R}_{\mathrm{V}, \text { Hold-down }}\right)$;

- Hold-down connection between floors (in the case of multi-storey buildings).

These are illustrated in Figure 29 for a wall panel with 2 segments. However, the principle can be extended to any number of wall segments.

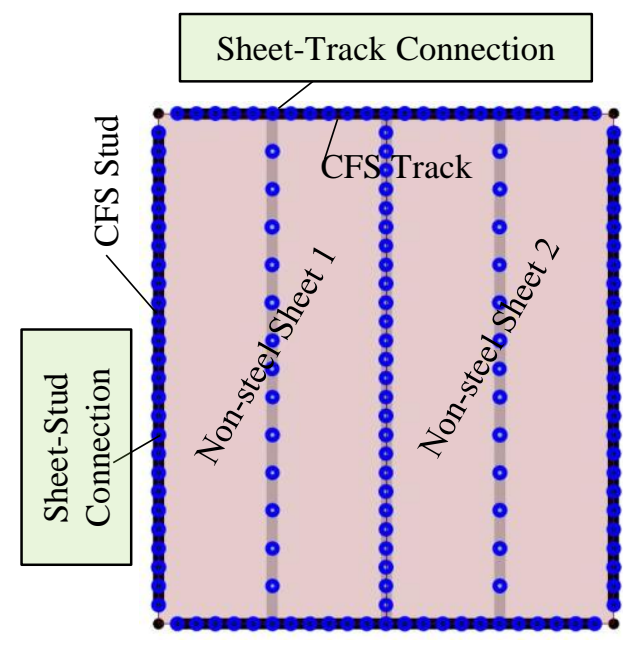

a) Identification of components

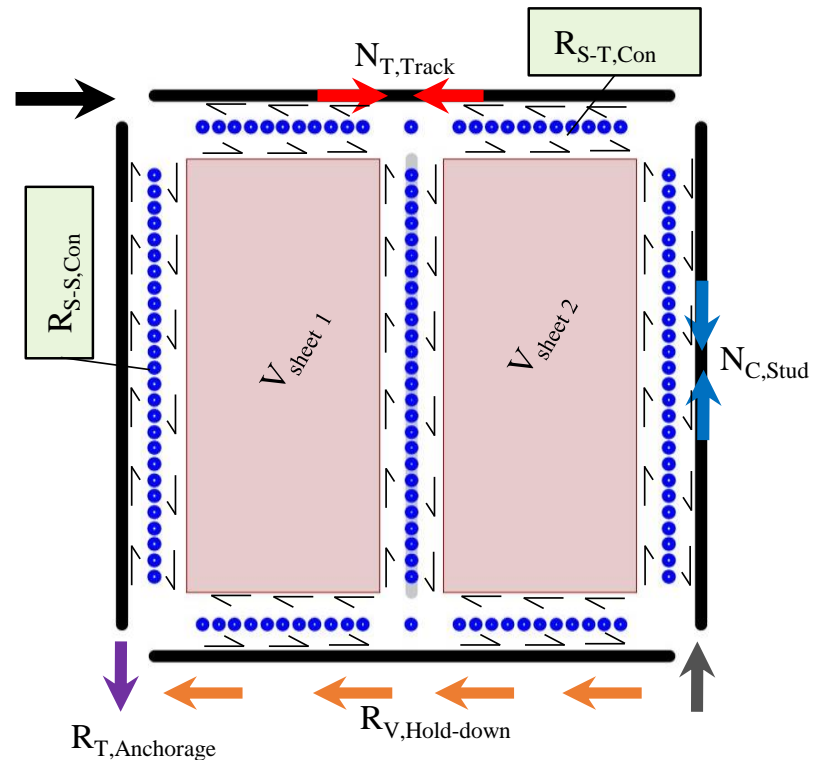

b) Load path

Figure 29: LSF braced with non-steel sheet or panel

The evaluation of the above components of the system, except for the non-steel sheet or panel and the Sheet -to-Stud/Track connection, can be performed using the design rules for the design of steel strap braced LSF walls (see §3.2). In relation to the components involving non-steel elements, when these are wood derivate, 
the design prescriptions in EN 1995-1 [18] may be adopted. In fact, in housing the structural system in timber construction is similar to the structural system in LSF. Contrary to EN 1993-1-3 [16], EN 1995-1 [18] provides design guidance that can be used in this case, for example, the steel-to-timber connection presented in $\$ 2.2$.

On the other hand, AISI S213 [30] covers not only the "all-steel" LSF braced walls but also the LSF walls braced with non-steel sheet or panels. In this case, similar to the case of braced frame using steel straps, the resistance of the wall to lateral loading is governed by the smallest resistance of the listed components where there is equilibrium between the external and internal forces, as given by Error! Reference source not found.

$$
F_{H, \text { max }} \leftrightarrow \operatorname{Min}\left(N_{C, \text { Stud }} ; N_{T, \text { Track }} ; V_{\text {Sheet }} ; R_{S-T, \text { Con }} ; R_{S-S, \text { Con }} ; R_{T, \text { Anchorage }} ; R_{V, \text { Hold-down }}\right)
$$

In the case of cyclic loading, the best structural response is obtained with failure of the Sheet -to-Stud/Track connection [39][40] as these connections fail in a ductile manner. In the experimental tests on walls governed by the connection response, no distinction in failure is noticed between monotonic and cyclic tests [10]. In what refers the behavior factors of the LSF walls braced with wooden boards, no analogy can be done with the structural systems covered in EN 1998-1 [35]. Different values are found in the literature. A value of 4 is proposed by [40]; while in AISI S213 [30], the value proposed for LSF walls with shear panels of other materials is 2. However, in [40] states that the latter values are conservative. Additional studies based on extensive dynamic nonlinear analysis are still required to further improve the accuracy of the behavior factor.

In relation to the lateral stiffness, the lateral deformation of the wall panel is obtained from the added contribution of different parts of the system [39][40], namely:

- Sheet or panels shear deformation $\left(d_{s}\right)$;

- $\quad$ Bending deformation $\left(d_{b}\right)$;

- Sheet-to-Track and Sheet-to-Stud deformation $\left(d_{f}\right)$;

- Overturning deformation $\left(d_{a}\right)$.

As referred above, the best performance of the wall panel is obtained when the governing component is the Sheet-to-Stud/Track connection. Only this component is assumed entering the non-linear range [40]. The complete determination of the force-deformation behavior of the wall subjected to lateral loading is complex and usually requires the execution of experimental tests. In this case, the load-displacement curve can be derived using the relationship proposed by [41] and a detailed description of the model is found in 
1 [40]. Although this approach is able to provide an accurate estimate of the response of the wall to lateral loading [39][40], it is not practical for design purposes as it requires the execution of experimental tests. However, the approach is suitable for the execution of advanced numerical studies, for example, to assess the seismic performance of LSF structures accounting for the contribution of non-steel sheets/panels.

\section{Experimental tests on light steel framing panels subject to lateral loading}

\subsection{General}

In order to characterize the behaviour of light steel framing panels subject to lateral loading, full-scale experimental tests were conducted within the scope of the research project MODCONS: Development of modular construction systems for high-rise residential buildings [29]. These were limited to the testing of bare steel panels (unbraced) and steel panels "braced" by OSB boards. The main goal of these tests was to assess the contribution of the OSB board to the stiffness of the panel. It is noticed that the tests were performed based on the configuration of the light steel framing panels developed for the commercial modular construction system CoolHaven ${ }^{\circledR}$ [15]. In this construction system, the vertical studs have different cross-section from the usual channel section $(\mathrm{C})$ due to the particularly of the on-site panels assembling system. Nevertheless, the main purpose was to characterize the lateral response of the panels, which is mainly influenced by the use of OSB board and not by the shape of the cross-section.

\subsection{Experimental Campaign}

\subsubsection{Experimental programme}

A total of six full-scale tests were performed. The specimens' configuration consisted in standard light steel framing panels used in the CoolHaven construction system [15], as illustrated in Figure 30. In order to characterize the lateral behaviour of the panel, the main variables were: i) bare steel panel or OSB board "braced" panel; and ii) the distance of the screws for the connection between the OSB board and steel profiles. Table 9 summarizes the experimental programme. Three series of two tests were considered. The loading consisted in a static monotonic lateral load applied at the top of the panel. 


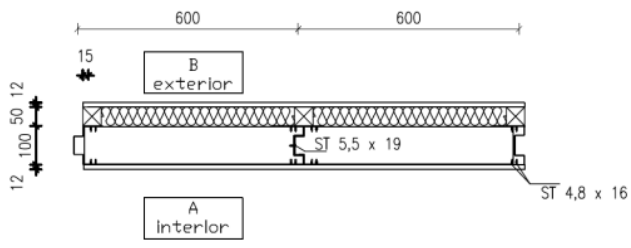

a) Panel cross-section

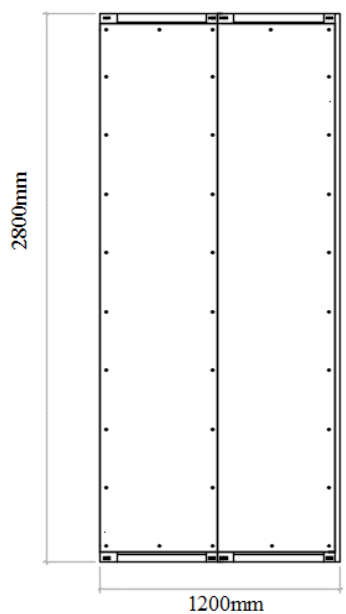

b) Panel elevation

\begin{tabular}{|c|c|c|}
\hline Test ID & Type & Variable \\
\hline $\begin{array}{l}\text { Test } 01 \\
\text { Test } 02\end{array}$ & Bare steel frame & No OSB board \\
\hline Test 03 & \multirow{4}{*}{ Frame braced by OSB board } & OSB board - steel frame screw connection spacing $\rightarrow 300$ \\
\hline Test 04 & & $\mathrm{~mm}$ \\
\hline Test 05 & & OSB board - steel frame screw connection spacing $\rightarrow 150$ \\
\hline Test 06 & & $\mathrm{~mm}$ \\
\hline
\end{tabular}

Figure 30: General configuration of the LSF panel from Cool Haven construction system [15]

Table 9: Experimental programme on LSF panels subject to lateral loading
3

4

5

6 


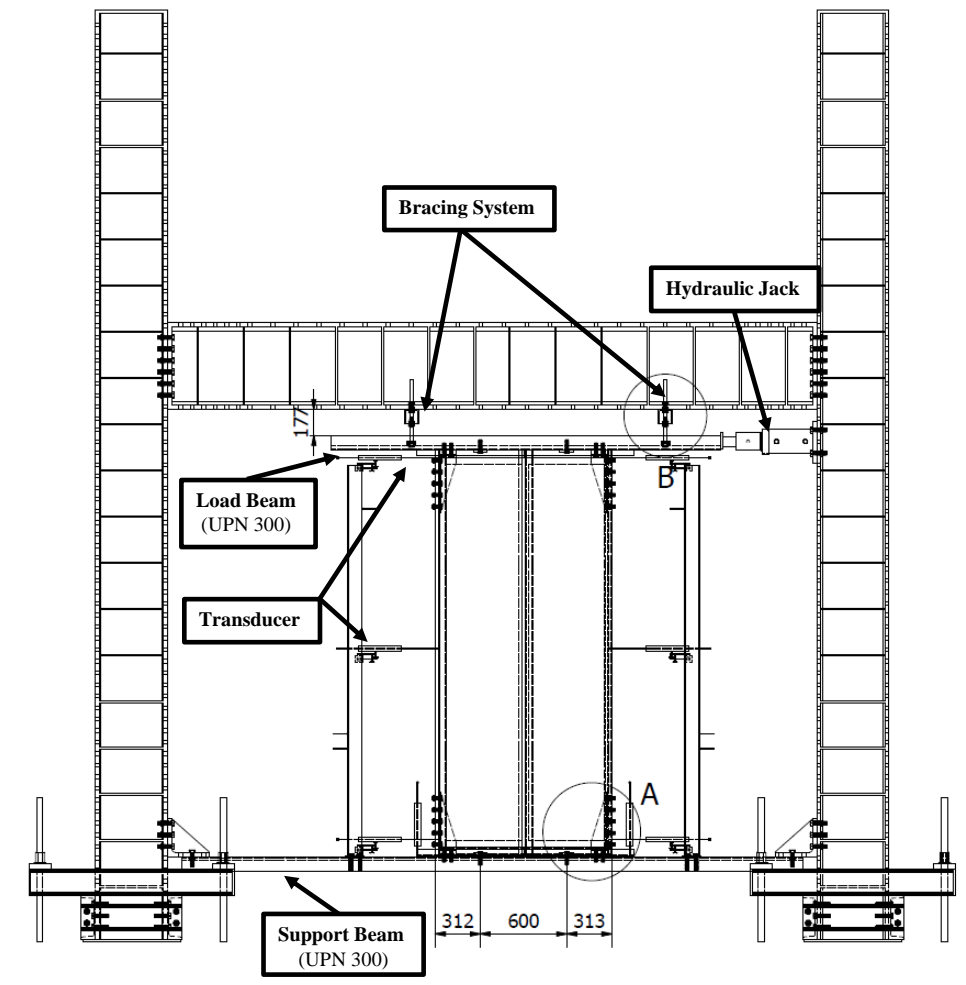

Figure 31: Experimental layout of the LSF panels subject to lateral loading

4.2.3 Experimental process

The test procedure was based on the standards ASTM E564-06 [42] and ASTM E72 [43]. At least two tests

should be performed for assembly/wall to determine the resistance capacity of the wall module. According to these standards, the load is applied on the top of the wall module, in the centre of the steel frame using a

hydraulic jack able to maintain a displacement rate constant until the ultimate force is reached.

For monotonic static tests, a pre-load of $10 \%$ of the estimated ultimate force should be applied or at least

9 five minutes for the connections. The load shall be monitored with a load cell. Figure 32-a) and Figure 32-

b) show the displacement points that should be measured and the calculation of the horizontal displacement

11 according to ASTM E564-06 [42], respectively. 


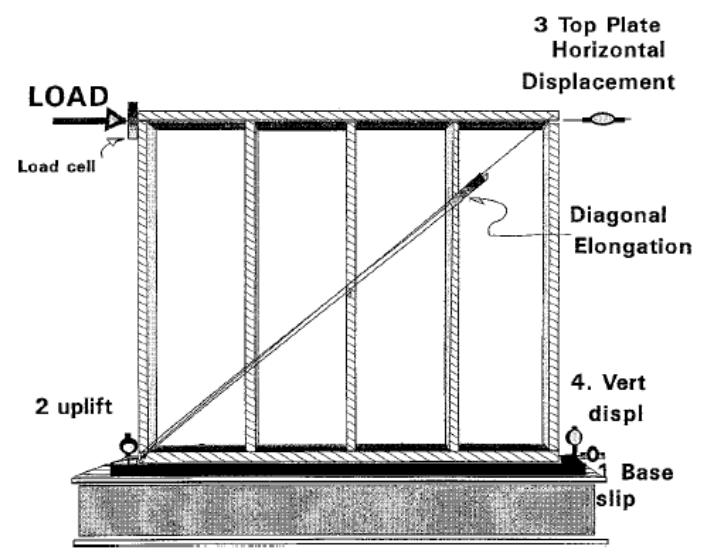

a) Panel frame configuration

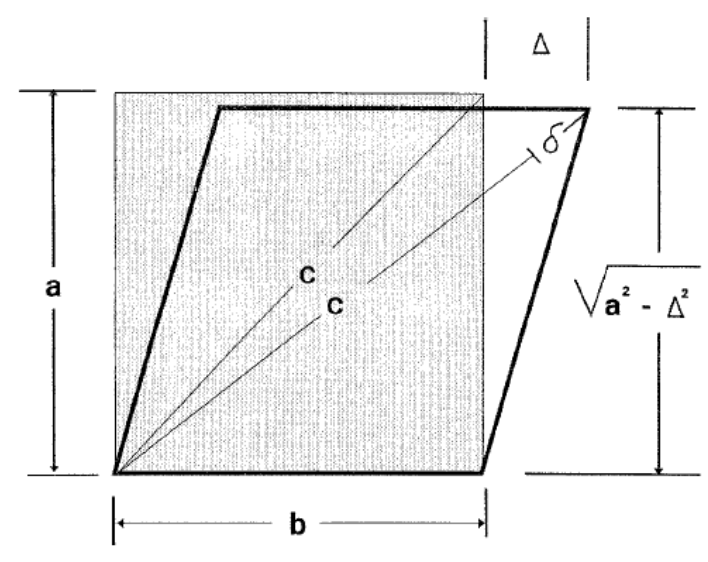

b) Horizontal measurements
2 Four displacement transducers are used to directly measure the deformation in four fundamental points, as

3 illustrated in Figure 31. Based on the horizontal and vertical displacement measurements of these four

$$
\Delta_{\text {int }}=\Delta_{3}-\Delta_{1}-\left(\Delta_{2}-\Delta_{4}\right) \times \frac{a}{b}
$$

5 Then, the internal shear stiffness $(G)$ of the wall-panel is given by expression (14):

$$
G=\frac{P}{\Delta_{\text {int }}} \times \frac{a}{b}
$$

6 Since the behaviour of the wall-panel is non-linear, for the calculation of the internal shear stiffness a

7 reference load of $33 \%$ of the ultimate load $\left(P_{u}\right)$ is considered.

\section{$84.3 \quad$ Experimental results}

9 The experimental tests of all specimens (Figure 33) were conducted up to failure. In the bare steel panel,

10 failure occurred in the vertical stud by local instability of the profile (Figure 34-a). In the braced panels,

11 failure was observed in the connection between the OSB board and the steel profile (Figure 34-b). 


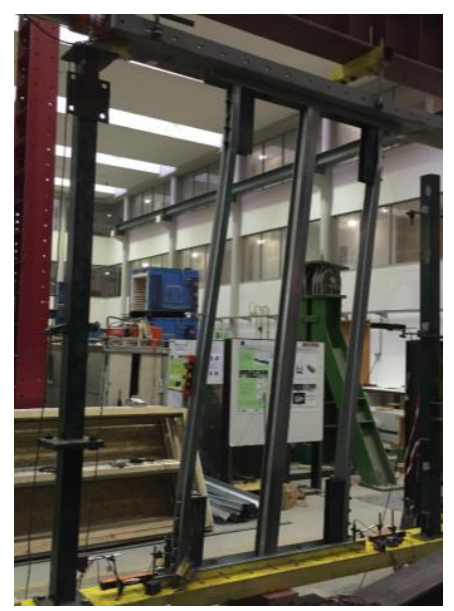

a) Bare steel panel

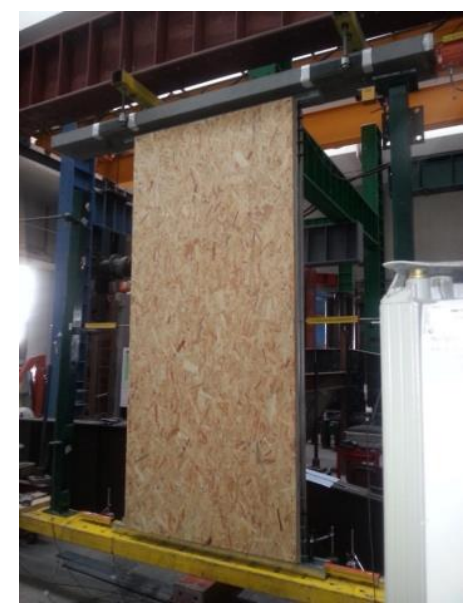

b) Braced panel with wood board

Figure 33: LSF panels test specimens

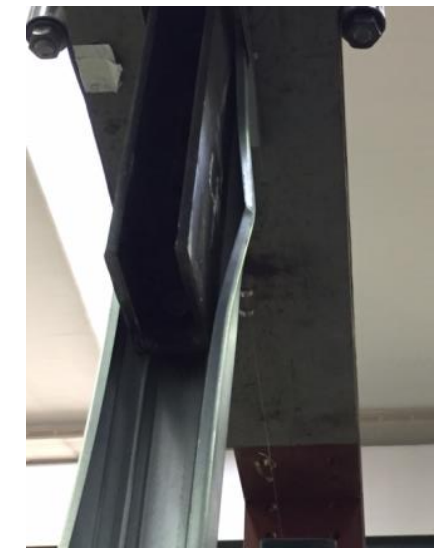

a) Bare steel panel

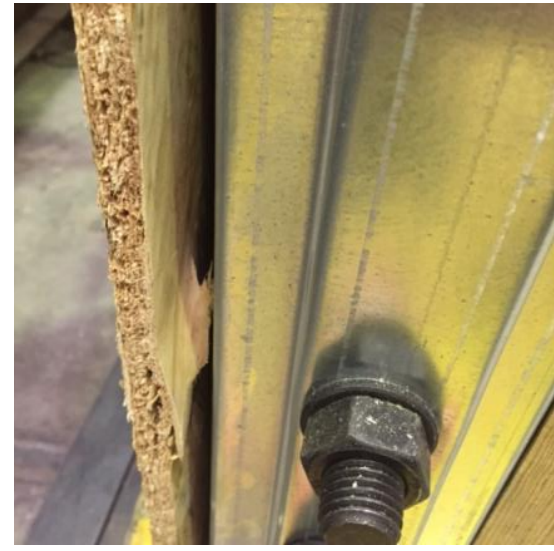

b) Braced panel with wood board

Figure 34: Failure on the LSF panel tests

The test results in terms of ultimate load $\left(P_{u}\right)$ and panel shear stiffness $(G)$ are summarized in Table 10 . The shear stiffness was determined based on a load corresponding to $33 \%$ of the ultimate force, as described before. The beneficial effect of the OSB board is evident. The latter was quantified using as reference the bare steel panel results and is shown in Figure 35. The deformability of the panels, especially of the bare steel panel is highly dependent on the shear screw connection between the profiles. Although the limited resistance of this type of connections, it was observed from the bare steel panel test that the screw connections did not limited the resistance of panel, as failure occurred with instability of the profile. Evidently this depend on the number of screws used in the connection between the steel profiles, but in the particular case of these tests, it depends on the hold-down systems at the corners required by the test standards. On the other hand, the screw connections between the OSB board and the steel profile confirmed 
to be a limitation to the lateral resistance of the panel. This is evident, as with the increase of the number of screws the lateral resistance also increased.

Table 10: Summary of the results of the experimental tests on light steel framing panels subject to lateral loading

\begin{tabular}{|c|c|c|c|c|}
\hline Test ID & $\begin{array}{l}\text { Ultimate load } \\
\qquad[\mathrm{kN}]\end{array}$ & $\begin{array}{l}\text { Average ultimate } \\
\text { load }[\mathrm{kN}]\end{array}$ & $\begin{array}{c}\text { Panel shear } \\
\text { stiffness G } \\
{[\mathrm{N} / \mathrm{mm}]}\end{array}$ & $\begin{array}{c}\text { Average panel } \\
\text { shear stiffness } G \\
{[\mathrm{~N} / \mathrm{mm}]}\end{array}$ \\
\hline Test 01 & 3,91 & \multirow{2}{*}{3.99} & 79,00 & 90,68 \\
\hline Test 02 & 4,06 & & 102,35 & \\
\hline Test 03 & 17,47 & \multirow{2}{*}{17.47} & 965,10 & 960,45 \\
\hline Test 04 & 17,46 & & 955,80 & \\
\hline Test 05 & 24,40 & \multirow[t]{2}{*}{25,85} & 904,00 & 900,50 \\
\hline Test 06 & 27,30 & & 897,00 & \\
\hline
\end{tabular}

5

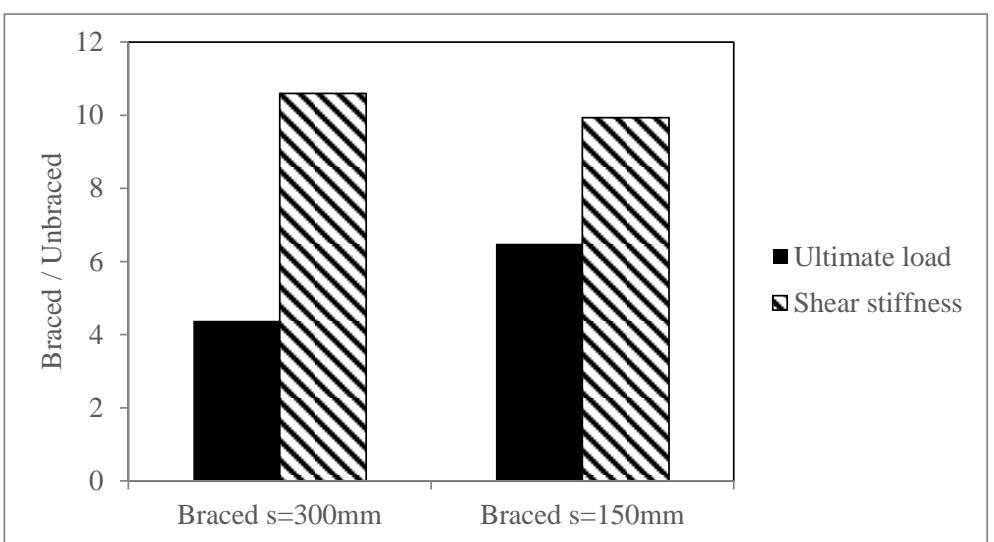

Figure 35: Quantification of the contribution of the OSB boards.

The force-displacement curves obtained in the tests are present in Figure 36. In these curves, the force represents the total lateral load applied at the top of the panels and the displacement corresponds to the horizontal displacement measured at the top of the panel. These curves put in evidence the differences between the test specimens. The tests on the bare steel frame (Test 01 and Test 02) show a very flexible behaviour with low load capacity and high deformation capacity. The specimens with the OSB board (Test 03 to Test 06) show a considerably higher lateral stiffness and load capacity in comparison to the bare steel frame. The increase is in order of 4 to 5 times the value obtained for the bare steel frame. Therefore, the OSB board has a non-negligible impact on the frame. Furthermore, these two series of specimens confirm 
1 that the number screws fixing the OSB board to the steel frame is directly related with the lateral load 2 capacity of the panel. The higher the number of screws, the higher the load capacity.

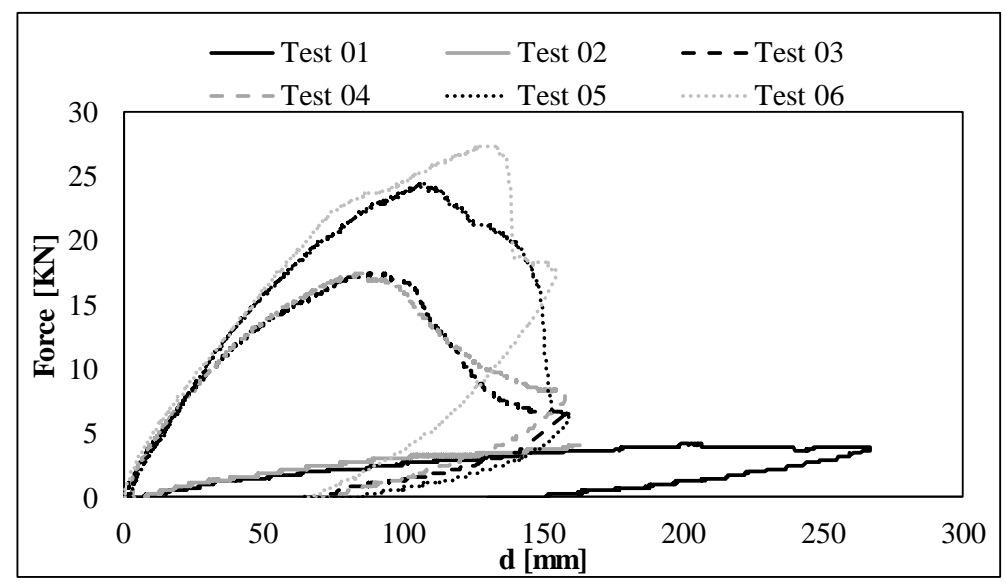

Figure 36: Force-deformation results of the experimental tests on light steel framing panels subject to lateral loading

Figure 37 provides a global comparison between the results of experimental tests available in the literature [10], the experimental results obtained by the authors of this paper and the application of the analytical method, described in $\$ 3.3$. Given the different dimensions, material and geometric properties of the walls, the comparison is made using the ultimate resistance ratio and the corresponding screws spacing ratio. As observed in this figure, there is a deviation between the experimental tests performed by the authors and the experimental tests provided by [10]. This difference is not observed between the two type of walls (different dimensions) reported in [10]. This may indicate that the observed difference is not due to the size of the wall but due to the different construction system used. Then, in relation to the analytical results, a higher deviation is observed. This was expected mainly because of the conservative results already observed in OSB-steel connections, discussed in §2.2. Furthermore, as demonstrated in the results of the bare steel wall frame presented in Figure 36, there is a frame effect that is not taken into account in the analytical model. Nevertheless, although differences are observed, the governing mode of failure is the same: the sheet-to-track connection. 


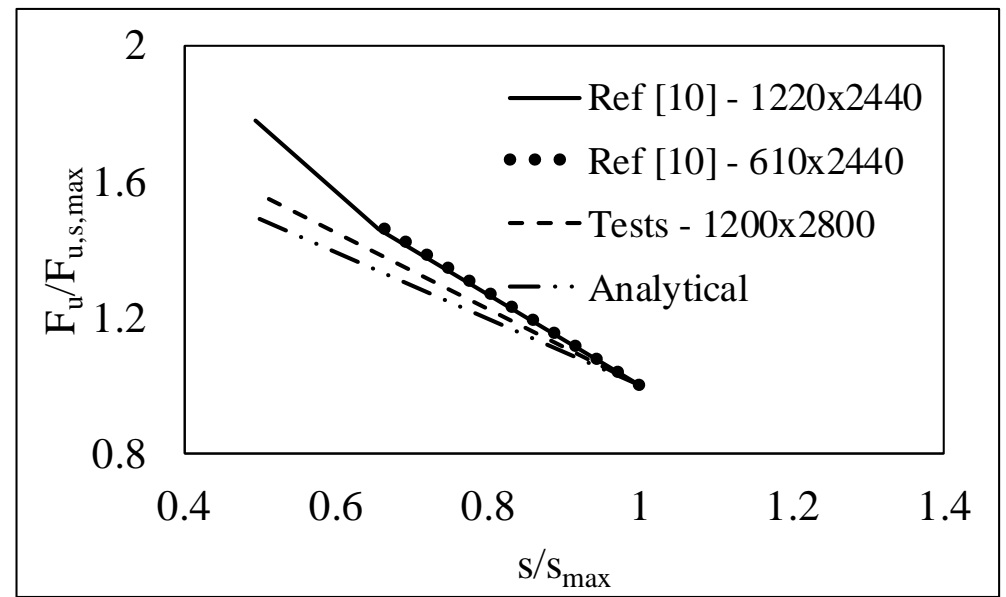

Figure 37: Comparison between literature tests, performed tests and analytical model

\section{Numerical investigations on light steel framing panels to lateral loading}

\subsection{General}

Given the limitation of the experimental tests and in order to further investigate the contribution of the OSB board in comparison with a steel-braced and non-braced panel, numerical simulations were performed and they are hereafter discussed.

The numerical models were developed in the finite element software Abaqus [26]. Only two type of panels were simulated. The first model is a reproduction of the experimental test on the bare steel frame for a validation purpose. Then, a second model simulates the same bare steel frame incorporating standard steel bracing using flat steel strips.

The main characteristics of the developed models are the following:

- The steel cold-formed profiles, including bracings, are simulated by means of shell elements (S4R);

- No initial imperfections, local and global, were considered;

- The simulations consisted in a push-over analysis reproducing the experimental tests. The load was applied at the top of the frame;

- The analysis considered geometric and material non-linearities;

- The material behaviour used for the steel profiles is an elastic-perfectly-plastic law;

- The screw connections used to assemble the cold-formed profiles are considered as fully rigid (only in the screw position); 
- The screw connections used to connect the diagonal steel straps to the cold-formed profiles are considered as fully rigid (the number of screws was assumed so that the connection is not a limitation);

- The anchorage of the panel is also assumed as rigid.

Taken into account the above characteristics, the main limitations of the developed numerical model are the following: i) the numerical model cannot reproduce the complete response of the panel to lateral loading when the behaviour is governed by the connections; and ii) accuracy can only be obtained while the connections remain in the elastic range. Nevertheless, the main purpose of this model is to evaluate the influence of OSB sheets on the lateral response of LSF walls through the comparison with common brace system using steel straps. In the next sub-sections the validation of the model and the efficiency of the different systems against the lateral loading of the panels are discussed.

\subsection{Validation and calibration of the developed FEM}

The comparison between the force-displacement curves obtained from the numerical model and the measurements from the tests is presented in Figure 38. The force and the displacement represent the total applied load and the displacement at the top of the frame in the direction of the applied load, respectively. A good agreement for the initial stiffness is observed. After $1.5 \mathrm{kN}$ load, a deviation is noticed, being the experimental result more flexible. This deviation is justified by the screw connection modelling which is assumed more rigid in the numerical model than in the experimental test. In the experiments with increasing load a rotation of the screw occurs. With the rotation of the screws, the plates (member flanges) are blocked by the screws threads. Whenever a thread traverses the plate there is a slip in the structure response until the next thread starts working effectively. As result of this behaviour a more deformable structure is obtained. The different plateau in the force-deformation curve of the experimental tests reproduces this mechanism. In what concerns the maximum lateral load, the agreement is excellent. Figure 39 compares the deformation of the bare steel frame obtained in the experimental tests and in the numerical simulation. Comparing with the experimental deformation, it can be observed that the global behaviour of the test is well reproduced. From these results it can be concluded that the developed model provides an acceptable accuracy to perform further analysis of different bracing solutions, as it is presented in the next section. 


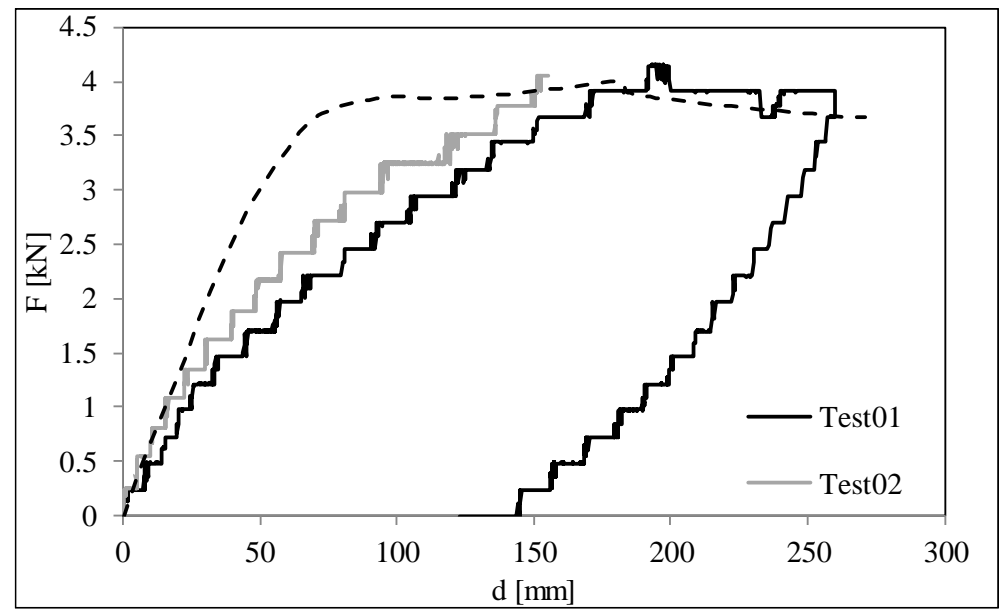

2 Figure 38: Force-displacement curve comparing experimental results with numerical simulations.
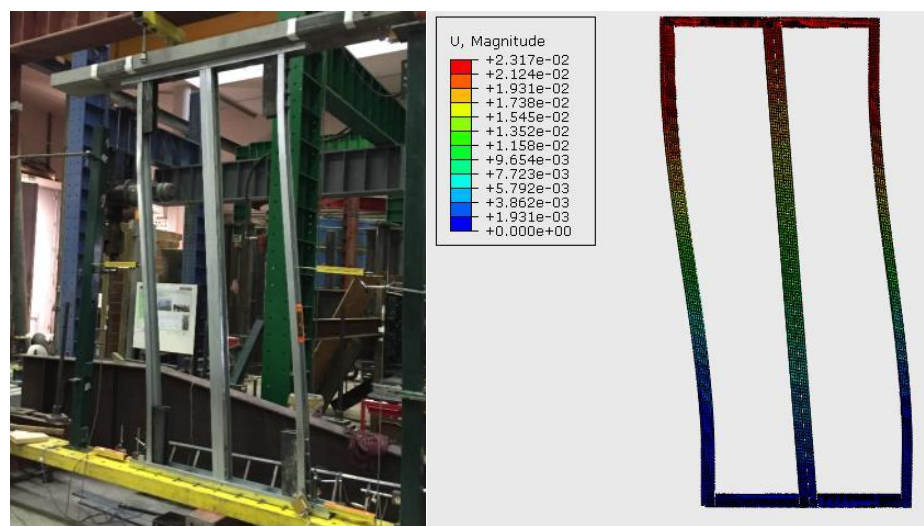

$5 \quad$ Figure 39: Numerical deformation of the bare steel frame

\subsection{Structural performance of light steel framing panels to lateral loading}

In LSF structures, the bracing system is usually achieved by means of steel elements. A common solution is the use of flat steel strips. This is the case of the CoolHaven modular construction system [15]. In order to compare the contribution of the OSB board to this classical solution, a second numerical model was developed. The model, illustrated in Figure 40, consist in the modification of the model validated in the previous section, through the integration of steel flat stripes (panel lateral bracing). According to the CoolHaven construction system [15] the standard solution relies in flat stripes of $100 \mathrm{~mm} \times 1.5 \mathrm{~mm}$; however, this depends on the design situation. It should be noted that this model was only used to evaluate the impact on the panel initial lateral stiffness. The load capacity of the braced panels is often governed by the connection between brace and stud, and therefore it depends on the number of screws used. However, as demonstrated in section 2.1 .4 , in the elastic range the behaviour of connection is almost rigid. Thus, the number of screws will not affect the initial stiffness of the braced panel. 
1 The validation of the model for the simulation of the initial lateral stiffness of the panel is illustrated in

2 Figure 41. The numerical force-deformation curve is compared with the panel initial lateral stiffness 3 obtained in the monotonic tests reported in [38] on bare steel LSF walls braced with steel straps. In order 4 to make this comparison, the initial lateral stiffness of the tests was modified using the following factors:

5 i) diagonal steel strap cross-section area $\left(A_{N u m} / A_{\text {Test }}\right)$; ii) length of the diagonal steel strap ( $\left.L_{\text {Test }} / L_{\text {Num }}\right)$; iii)

6 and the angle of the diagonal with the horizontal $\left(\operatorname{Cos}^{2} \alpha_{\text {Num }} / \operatorname{Cos}^{2} \alpha_{\text {Test }}\right)$. In the "normalization" of the test

7 results only the described factors were used because the initial stiffness is mainly affected by the deformation of the diagonal steel strap, and therefore, the other components (see §3.2) can be neglected in a simplified approach. As it can be observed the approximation is very accurate.

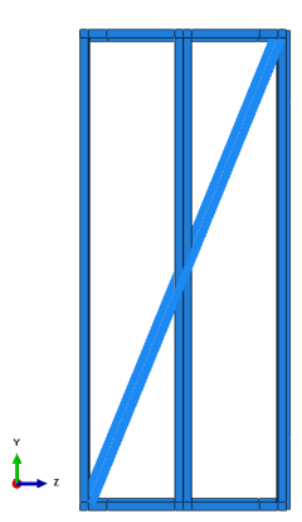

Figure 40: Model with Figure 41: Comparison between numerical model and test reported in [38] steel bracing system.

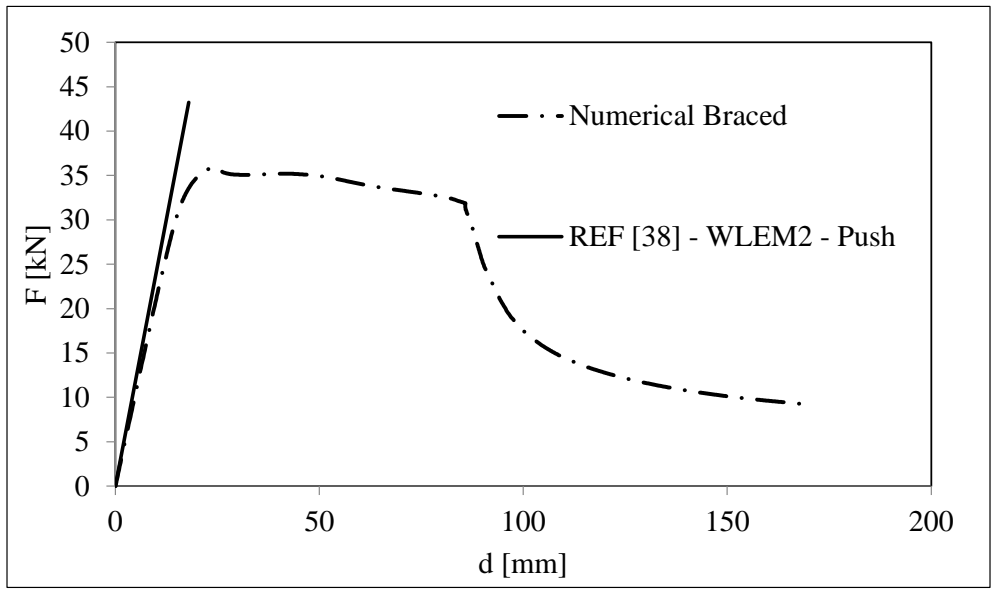

Figure 42 presents the force-deformation curve for both numerical models (braced and unbraced frame) and all experimental tests described before. As expected, the results show that the LSF panel with steel bracing provides the highest stiffness. In addition, and in spite of the difference between the steel braced panels and the panels using OSB boards, it is observed that OSB boards provide a significant contribution to the lateral stiffness of the panel. The same trend was also observed in studies from other authors [4],[6], although the results may not be compared as different panel configurations and connections were used. 


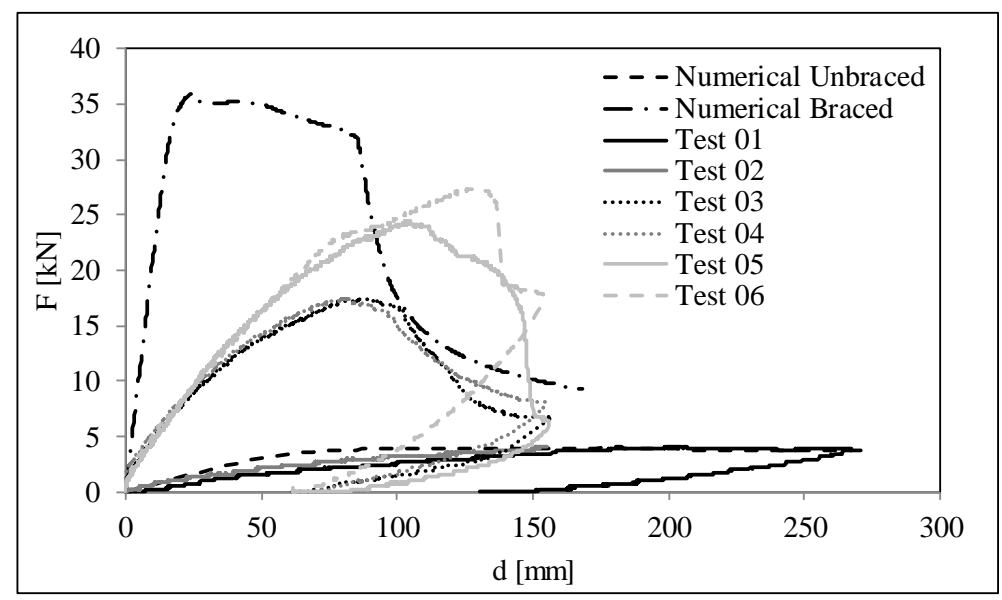

Figure 42: Force-deformation curves comparing numerical simulations and experimental tests of LSF panels subject to lateral loading

1 The differences of the lateral stiffness between the three solutions (bare steel framed panel, steel braced panel and OSB braced panel) are the following:

- The ratio between steel braced panel $\left(S_{\text {ini }}=2127 \mathrm{~N} / \mathrm{mm}\right)$ and the unbraced steel panel $\left(S_{\text {ini }}=\right.$ $60 \mathrm{~N} / \mathrm{mm}$ ) is approximately 35.5 ;

- The ratio between the steel braced panel $\left(\mathrm{S}_{\mathrm{ini}}=2127 \mathrm{~N} / \mathrm{mm}\right)$ and the steel panel braced by the OSB board $\left(\mathrm{S}_{\mathrm{ini}}=332 \mathrm{~N} / \mathrm{mm}\right)$ is approximately 6.4 .

\section{Conclusions}

This paper presented an integrated approach for assessing the behaviour of Light Steel Framing panels subjected to a lateral load using screw connections. The investigations reported comprised the behaviour of the steel-to-steel screw connections, OSB-to-steel screw connections and the global behaviour of LSF panels subject to lateral load. Both types of connections have non-negligible influence on the response of the latter. The stiffness and the resistance of the panels, subjected to lateral loading, are influenced by the response of these connections.

In relation to the investigations on the behaviour of steel-to-steel screw connections, numerical, experimental and analytical studies were presented. The comparison between the experimental tests and the analytical approach, show that the AISI approach provides more accurate results than the EN 1993-13, which is more conservative. The numerical calculations showed that the deformation only due to the connection is negligible in comparison to the deformations that may arise in other parts or due to eccentricities. Therefore, assuming this connection as rigid is a reasonable approach. 
1 The experimental investigations on OSB-to-steel screwed connections show some variability on the postelastic resistance. This variability is due to the fact that the failure is governed by the OSB part of the connection which presents a high variability on the mechanical properties. This is particular relevant in an ultimate strength of the material, which is governed by the highly non-uniform microstructure of the material. The comparison between the analytical approach provided in EN 1995-1-1 and the experimental tests shows a conservative approach of the code. However, this is justified by the high variability on the material properties of the OSB board.

The comparison between the panel using flat steel strips and the panel using OSB board, for the lateral bracing, showed that the contribution of the latter is significant and therefore it is a consistent solution for the lateral stability of LSF structures. Currently, the EN 1993-1-3 completely disregards this type of construction element in LSF construction. This is not the case of the AISI that addresses the use of these elements for the lateral stability of LSF structures. The test results showed that the connection between the timber or timber derived boards and the steel frame influence the lateral load capacity and lateral stiffness of the panel. Nevertheless, the contribution of OSB boards to the lateral loading of the LSF panels has been demonstrated to be effective and should be taken into account. A revision of the EN 1993-1-3 in order to address the contribution of timber derived boards on the lateral stiffness of LSF is therefore recommended.

\section{References}

[1] Lee Y H, Tan C S, Mohammad S, Tahir M Md and Shek P N. Review on Cold-formed Steel Connections, The Scientific World Journal, Hindawi Publishing Corporation.

[2] Serrette, R., \& Ogunfunmi, K. (1996). Shear Resistance of Gypsum-Sheathed Light-Gauge Steel Stud Walls. Journal of Structural Engineering, 122(April), 383-389.

[3] Tian, Y. S., Wang, J., \& Lu, T. J. (2004). Racking strength and stiffness of cold-formed steel wall frames. Journal of Constructional Steel Research, 60(7), 1069-1093.

[4] Vieira, L. C. M., \& Schafer, B. W. (2012). Lateral stiffness and strength of sheathing braced coldformed steel stud walls. Engineering Structures, 37, 205-213.

[5] Buanopane S G, Bian G, Tun T H and Schafer B W (2015). Computationally efficient fastenerbased models of cold-formed steel shear walls with wood sheathing, Journal of Constructional Steel Research, 110: $137-148$.

[6] Baran, E., \& Alica, C. (2012). Behavior of cold-formed steel wall panels under monotonic horizontal loading. Journal of Constructional Steel Research, 79, 1-8. 

seismic design of lightweight structures. Part 1. Screwed joints in straps", Thin-Walled Struct. 44, 197210.

Fiorino, L., Della Corte, G., Landolfo, R. (2007). Experimental tests on typical screw connections for cold-formed steel housing. Engineering Structures. Elsevier Science. ISSN 0141-0296. Vol. 29, pp. $6 \quad 1761-1773$.

7 [9] Serrette, R. L., Encalada, J., Juadines, M., and Nguyen, H. (1997). "Static racking behavior of plywood, OSB, gypsum, and FiberBond walls with metal framing.” J. Struct. Eng., 123(8), 1079-1086. [10] A.E. Branston, C.Y. Chen, F.A. Boudreault, and C.A. Rogers (2006). Testing of light-gauge steelframe - wood structural panel shear walls Can. J. Civ. Eng. 33: 561-572.

[11] Fulop L and Dubina D. (2004) Design criteria for seam and sheathing-to-framing connections of cold-formed steel shear panels, Proceedings of the 17th international specialty conference on cold-formed steel structures, p. 743-59.

[12] Lange J., B. Naujoks B. (2006). Behavior of cold-formed steel shear walls under horizontal and vertical loads. Thin-Walled Struct, 44 , pp. 1214-122.

[13] Fiorino L., Iourio O., Landolfo R. (2009). Sheathed cold-formed steel housing: a seismic design procedure Thin-Walled Struct, 47, pp. 919-930.

[14] Corner S M W (2014). Screw-Fastened Cold-Formed Steel-to-Steel Shear Connection Behavior and Model, Master of Science in Mechanical Engineering, Virginia Polytechnic Institute and Sate University.

[15] Henriques J, Gervasio H, Rodrigues J and Simões da Silva L (2014). Cool Haven innovative construction system for buildings - Case study: "CAP Solidarité à la Croix Valmer, France”, Proceedings of the 7th European Conference on Steel and Composite Structures, Eurosteel 2014, Naples, Italy. [16] CEN (2006). EN 1993-1-3: Eurocode 3 - Design of steel structures - Part 1-3: General rules Supplementary rules for cold-formed members and sheeting, European Committee for Standardization, Brussels, Belgium.

AISI (2007). AISI S100: North American Specification for the Design of Cold-Formed Steel Structural Members, American Iron and Steel Institute, Washington, D. C. 
1 [19] Davies JM (1991). Connections for cold-formed steelwork. In: Design of Cold-Formed Steel

2 Members (Rhodes J, Editor), Elsevier Applied Science, London and New York.

3 [20] Corner SMW (2014). Screw-fastened cold-formed steel-to-steel shear connection behavior and models, Master Thesis, Virginia Polytechnic Institute and State University.

5 [21] Simões da Silva, L (2008). Towards a consistent design approach for steel joints under generalized 6 loading. Journal of Constructional Steel Research, 64, pp. 1059-1075.

7 [22] LaBoube R and Sokol M (2002). Behaviour of screw connections in residential construction, Journal of Structural Engineering, 128(1): 115-118.

9 [23] Garcia F, Henriques J, Gervasio H and Simões da Silva L (2013). Análise de painéis com perfis de aço enformados a frio para utilização em construção modular, Actas do IX Congresso de Construcão Metálica e Mista, Porto, Portugal (in Portuguese).

[24] SFS Intec (2002). Self-drilling screw SL3-F-4.2x15 Technical Specification. www.sfsintec.biz

FABORY (2013). Self-drilling screw ST4.8x13 Technical Specification. www.fabory.com

[26] Abaqus (2011). Abaqus (6.11). Theory Manual and Users Manual, Dassault Systèmes Simulia Corp., 2011.

[27] Henriques J, Simões da Silva L and Valente I (2013). Numerical modelling of composite beam to reinforced concrete wall joints: Part I: Calibration of joint components, Engineering Structures, Volume 52, Pages 747-761, July 2013.

[28] AISI (2015). AISI S400-15: North American Standard for Seismic Design of Cold-Formed Steel Structural Systems, American Iron and Steel Institute, Washington, D. C.

[29] FP7 (2015). MODCONS - Development of modular construction systems for high-rise residential buildings, Deliverable D1.5 - Report on full-scale module tests for module type 2, Seventh Framework Programme.

[30] AISI (2012). AISI S213-07 w/ S1-09: North American Standard for Cold-Formed Steel Framing - Lateral Design, 2007 Edition With Supplement 1 (Reaffirmed 2012), American Iron and Steel Institute, Washington, D. C.

[31] Landolfo R, Fiorino L and Della Corte G (2007). Seismic response of light weight cold-formed steel low-riseresidential buildings:modelling based on screw connection testresults.In:Mazzolani F M,editor. Innovative steel structures for seismic protection of buildings:design criteria and methodologies — PRIN 2003, Polimetrica Publisher, pp.203-250. 
1 [32] Fülöp L A and Dubina D (2004). Performance of wall-stud cold-formed shear panels under

2 monotonic and cyclic loading. Part I: Experimental research, Thin-Walled Structures, 42:321-338.

3 [33] Fülöp L A and Dubina D (2004). Performance of wall-stud cold-formed shear panels under monotonic and cyclic loading. Part II: Numerical modelling and performance analysis”, Thin-Walled Structures, 42:339-349.

6 [34] CEN (2017). EN 1993-4: Eurocode 2 - Design of concrete structures - Part 4: Design of fastenings

7 for use in concrete, European Committee for Standardization, Brussels, Belgium.

8 [35] CEN (2005). EN 1998-1: Eurocode 8 - Design of structures for earthquake resistance - Part 1:

9 General rules, seismic actions and rules for buildings, European Committee for Standardization, Brussels, 10 Belgium.

11 [36] Macillo V, Iuorio O, Terracciano M T, Fiorino L and Landolfo R (2014). Seismic response of Cfs strap-braced stud walls: Theoretical study, Thin-Walled Structures, 85:301-312.

13 [37] Fiorino L, Terracciano M T and Landolfo R (2016). Experimental investigation of seismic behavior of low dissipative CFS strap-braced stud walls, Journal of Constructional Steel Research, Elsevier Science, 127:92-107.

[38] Iuorio O, Macillo V, Terracciano M T, Pali T, Fiorino L and Landolfo R (2014). Seismic response of Cfs strap-braced stud walls: Experimental investigation, Thin-Walled Structures, Elsevier Science, $85: 466-480$.

[39] Branston A E, Boudreault F A, Chen C Y and Rogers C A (2006). Light-gauge steel-frame - wood structural panel shear wall design method, Canadian Journal of Civil Engineering, 33:872-889.

[40] Fiorino L, Iuorio O and Landolfo R (2009). Sheathed cold-formed steel housing: A seismic design procedure, Thin-Walled Structures, 47:919-930.

[41] Richard R M and Abbott B J (1975).Versatile elastic-plastic stress-strain formula. Journal of Engineering Mechanics Division - ASCE, 101(4):511-515.

[42] ASTM E564-06 (2012). Standard Practice for Static Load Test for Shear Resistance of Framed Walls for Buildings, ASTM International, West Conshohocken, PA. Construction, ASTM International, West Conshohocken, PA. 